\title{
A Smart Production Process for the Optimum Energy Consumption with Maintenance Policy under a Supply Chain Management
}

\author{
Shaktipada Bhuniya ${ }^{1}\left(\mathbb{D}\right.$, , Sarla Pareek ${ }^{1}(\mathbb{D})$, Biswajit Sarkar ${ }^{2, *(D)}$ and Bimal Kumar Sett ${ }^{3}$ (D) \\ 1 Department of Mathematics and Statistics, Banasthali Vidyapith, Banasthali 304 022, India; \\ shakti13math@gmail.com (S.B.); spareek13@gmail.com (S.P.) \\ 2 Department of Industrial Engineering, Yonsei University, 50 Yonsei-ro, Sinchon-dong, Seodaemun-gu, \\ Seoul 03722, Korea \\ 3 Department of Mathematics, Hooghly Mohsin College, Chinsurah 712 101, India; settbk@gmail.com \\ * Correspondence: bsarkar@yonsei.ac.kr or bsbiswajitsarkar@gmail.com; Tel.: +82-107498-1981
}

Citation: Bhuniya, S.; Pareek, S.;

Sarkar, B.; Sett, B.K. A Smart Production Process for the Optimum Energy Consumption with Maintenance Policy under a Supply Chain Management. Processes 2021, 9, 19. https:// doi.org/10.3390/pr9010019

Received: 17 October 2020 Accepted: 16 December 2020 Published: 23 December 2020

Publisher's Note: MDPI stays neutral with regard to jurisdictional clai$\mathrm{ms}$ in published maps and institutional affiliations.

Copyright: (C) 2020 by the authors. Licensee MDPI, Basel, Switzerland. This article is an open access article distributed under the terms and conditions of the Creative Commons Attribution (CC BY) license (https:// creativecommons.org/licenses/by/ $4.0 /)$.

\begin{abstract}
In the current socio-economic situation, smart products are essential for daily life. Energy is a very much related matter to smart products. To buy a smart product, people mostly care about that smart product's energy consumption and the price. There is always a tug-of-war between the price of the product and the energy consumption of that product. An energy-efficient smart production system is described in this study where the production is variable, and in the out-of-control state, it produces defective products. For prevention of the out-of-control state, preventive maintenance and restoration are used within the smart production system. The rework policy helps to profit from the defective products, and the warranty policy helps to motivate the users. This model applies an improved strategy to the production process and develops a new product that needs to be marketed. Finally, this model plays a vital role in creating smart products with moderate energy consumption at a minimal cost. The mathematical model is a non-linear profit maximization problem that is solved both analytically and numerically. The classical optimization technique founds optimum solutions. Different numerical examples and sensitivity analysis with graphs are used to validate the mathematical model.
\end{abstract}

Keywords: supply chain management; flexible production rate; marketing; smart production; maintenance; backorder

\section{Introduction}

The smart product manufacturing system is now vital and profitable. This idea has a direct and profound effect on human life through the supply chain. The motherboard of the laptop or the circuit within the smartphone is an example of smart products. These are the very thin, sophisticated, and fine things that need to be handled with care. These products are made through smart production. Each stage in the smart production system is crucial, and there are many stages to making them perfect. The error may increase if the human or machine capacity is limited. Thus, smart machines are used more than human labor. The smart products need a more improved technological machinery system rather than the traditional production system. One of the features of smart production is the use of skilled labor, as necessary. The involvement of the labor within the smart production system is very significant. An imperfect production is a big push to this system (Sarkar [1]). There were more research from many directions of profitable business overcoming many more obstacles (Dey et al. [2]). In smart product production, a system may face a failure during production time or non-production time, and from there, the system is brought under in-control, and re-production is a challenging matter. In that case, to bring it under the in-control situation, the restoration during the production time and preventive maintenance policy 
during non-production time have been applied. Keeping the profitable matter in mind, the manufacturer uses the rework facility for imperfect products (Cárdenas-Barrón et al. [3]). Moreover, keeping in mind the customer popularity of smart products, the manufacturer has arranged the warranty period. Many previous research papers have mentioned these issues. An economic manufacturing quantity model was improved through rework and multiple shipments policy by Cárdenas-Barrón et al. [4], but the considerable demand was constant. Then, Sarkar et al. [5] considered a smart production system with a carbon footprint. Nakagawa [6] focused on the imperfect production with preventive maintenance. Sana [7] discussed an inventory-based model to control the imperfect production using preventive maintenance, rework, and warranty facility. However, in that inventory model, the production rate was constant, and the demand was deterministic. Khanna et al. [8] extend the Sana's [7] model by incorporating restoration cost, shipment cost, and, backorder cost. Nevertheless, the production rate and demand pattern remain unchanged. This model extends Khanna et al.'s [8] model by incorporating a variable production rate and selling price of the products, and energy consumption. Because who uses smart products can get more benefits by consuming minimal energy. This study is quite significant in this regard.

The smart production process has the technological benefit through which high-quality smart products can be produced by a few skilled workers in a short time. This model gives a modern outline of how to create smart products using smart production processes. Hence, this model aims to make smart products through a smart production process quickly with improved quality. Secondly, smart products' demand and popularity in the current market largely depend on their selling price and energy consumption. With this perception, the demand is depending on the selling price and energy consumption. As a result, the maximum profit and product popularity are achieved by reflecting the minimum selling price and minimum energy consumption. Third, this model aims to maintain a regular supply of products in the market through the concept of a variable production rate so that there is no shortage of products. Fourth, to address the system's failure, two measures have been taken here: to make the failed system suitable for re-production through restoration and to use preventive maintenance as a precaution against system failure.

The supply chain members jointly look at some of the issues to meet the demand for smart products in the global market and maximize profits, viz. making products, carrying them, and handing them over to the customer on time. This method can give far-reaching benefits to their economic and popularity fields. Moreover, the cordial relationship and transparent mentality between the SCM members are the primary tools for improving the total expected profit supply chain.

\section{Literature Review}

Smart products are a constant companion in the course of human life. We need it every moment, from waking up to going to sleep. Especially in the current dire situation, the need for it is increased. Convergence is becoming automated through smart products. So many previous research papers have done much research related to smart products. Sana [9] discussed an imperfect production model in which the production system suddenly changes to the out-of-control (OC) state from the in-control (IC) state. They considered the variable production rate with no shortages. Cárdenas-Barrón et al. [4] presented an economic manufacturing quantity (EMQ) model with replenishment policy. They introduced a rework policy for defective or scrap products. Khan et al. [10] proposed an SCM model in which quality improvement (QI) and setup cost reduction (SCR) plays an important role. Besides this, their model considered transportation discount policy and energy effect on the production process. Sarkar et al. [5] discussed a smart production model in which closed-loop SCM reduces the carbon and produces more perfect products in a logistics framework. Bhuniya et al. [11] expressed an inventory-based model of smart products with variable production rate. They introduced optimum energy consumption with a reduced failure rate and reworked policy to maximize the total profit. Dey et al. [12] formulated a model based on a smart production system. Their model introduced an au- 
tonomation policy for error-free inspection, as the defective rate was random and followed a different distribution. Sarkar and Sarkar [13] discussed a smart, sustainable production system that is very needed in the current situation. Their model gave a way to reduce waste and energy consumption. They included the autonomation policy for error-free inspection policy. Saxena et al. [14] discussed a closed-loop SCM model in which, for reducing the waste, defective products were reworked and remanufactured for the secondary market. Sarkar et al. [15] explained in their model of how autonomation policy control the out-ofcontrol situation while defective production took place. Their model is based on smart products with a marketing policy.

The contribution of maintenance policy to any production system is undeniable. This policy ranges from preventing system failures to increasing machine longevity. It is mainly applied during non-production. This kind of small investment in the case of enormous production costs increases the rate of production rapidly. Nakagawa [6] discussed an imperfect production model in which they introduced a preventive maintenance policy for the in-control situation. They considered the reworked policy of defective products. Sana [7] extended the previous model by considering the optimal buffer policy. He introduced the warranty policy for inventory control and to grow popularity. The previous research extended by Hsu and Hsu [16]. They considered an integrated inventory model of imperfect production where shortages are completely backorder. Jiao and Zhu [17] developed their model by introducing maintenance and renewable warranty. Khanna et al. [8] discussed a vendor-buyer SCM where preventive maintenance and restoration policy can easily control the out-of-control situation. Their model considered rework of defective products and gave a warranty policy of the products.

Backorder is an essential part of the supply chain, which is created due to several reasons. Because of this, the customer has any problems with the retailer. It can be of two types, partial or fully backorder. If the customer is waiting for the next delivery, it is called backorder altogether. Otherwise, it is called partial backorder. Much research has already been done depending on this topic. Wee et al. [18] discussed an economic production quantity (EPQ) model based on imperfect production and planned backorder. They introduced a rework policy of the defective products for remanufacturing. Sarkar et al. [19] presented a production type of model. They considered a random, imperfect production system, rework, and planned backorder in that EPQ model. Sarkar and Moon [20] developed an imperfect production model with the variable type of backorder. They introduced QI and SCR with a distribution-free approach. Liu et al. [21] studied a multi-product production with an integrated inventory model in which they considered preventive maintenance policy to reduce the defective production. Shin et al. [22] discussed a continuous review inventory model in which service level constraint was included to avoid backorder cost. Tiwari et al. [23] proposed a sustainable green production based supply chain model in which partial backorder and rework of defective items minimize the total cost. Kim et al. [24] offered an integrated inventory type of model through an improved way described to calculate the number of defective products. Besides this, their model incorporating backorder and quality control for a long-run process. Sarkar et al. [25] discussed a defective type of production model with random rework and planned backorder. They introduced remanufacturing of the reworked products to maintain the minimum total cost. Taleizadeh et al. [26] published an EPQ model of a multi-product production system with a single machine. They considered limited production capacity with delay-in-payments and partial backorder. Guchhait et al. [27] discussed a defective product-based production model with a backorder and warranty policy. Their model introduced QI matter and SCR to optimize the expected joint cost. Mishra et al. [28] discussed inventory management of deteriorating products based on backorder as well as controllable carbon emission. They considered preservation technology investment for the reduction of deterioration.

Variable production rate is a modern technique used to fulfill customer demand and control the market size. This concept can increase or decrease the producer's production status, depending on the market's average demand. Besides, this method is quite effective 
in controlling the production of any unusual situation. Many studies have been published on variable production rate such as Giri and Dohi [29] discussed an economic order quantity (EOQ) model by incorporating a variable production rate and machine breakdown Their model considered preventive and corrective repairing policy to control the machine breakdown. Chang et al. [30] proposed an assembly system-based EMQ model in which production rate was a variable type. Their model contained an imperfect process with a two-stage inventory. Sarkar et al. [31] discussed an integrated inventory model with a fixed production rate and Stackelberg game policy. Alduragam et al. [32] discussed an SCM in which demand-type was stochastic, and the production rate was variable. They introduced a full truck-load shipment policy, a new approach. Majumder et al. [33] formulated a supply chain model consisting of multi-retailer. They introduced a single-setup multipledelivery (SSMD) policy and lead time crashing concept with variable type production rate. Dey et al. [34] offered a supply chain model based on QI and SCR. They introduced a variable type of production rate to control the distribution-based demand. Dey et al. [12] presented a paper based on autonomation policy to control smart production inventory. They considered inspection policy with the variable type of production rate.

The demand is a sensitive issue in the supply chain. It may be constant or variable type. For variable demand, it may depend on a different matter such as selling price, advertisement, and stock. Depending on these different aspects, the producer has to control production. Many researchers have been already published on variable demand: Wu et al. [35] discussed a model in which the demand was based on the stock of products. Their model mainly formulated on non-instantaneous deteriorating types of products with backlogging. They compared the model with different cases such as fully backlogging and shortages. Feng et al. [36] discussed an inventory type of model in which the products' price and displayed a stock-based demand. They considered perishable products for environmental benefit. Noh et al. [37] developed a supply chain model in which demand depends on an advertisement and selling price. Besides, for smooth running business, there considered Stackelberg game policy. Meng et al. [38] developed SCM based paper in which energy consumption was distributed unequally among the members. The energy consumption based on their paper gave a new direction for the next research for considerable demand. Sarkar et al. [39] formulated a model where demand was based on unit selling price and permissible delay in-period for payments. They considered retailing and trade-credit for the deteriorating products. Malik and Sarkar [40] presented an SCM model in which demand is a function of lead time and diverse inventory. They approached a coordination game theory to achieve the maximum profit. Besides this, their model considered a flexible production concept with a bargaining strategy. Bhuniya et al. [11] studied a model in which the demand is a function of selling price and advertisement. They considered optimum energy consumption for smart products. Dey et al. [2] discussed an integrated inventory model in which demand depends on the selling price of the products. They also assumed that lead time demand follows a Poisson distribution.

A supply chain is a medium through which goods produced in one part of the world can easily reach other parts of the world. Its role in various aspects of reality is undeniable. Its work has been seen randomly in some previous research papers. Pal et al. [41] offered a model based on a multi-echelon supply chain. They introduced multiple market facilities if any supply disruption. In their model, defective or scraped products could sell to the secondary market after rework. Rad et al. [42] developed an SCM model by introducing the backorder and price-sensitive demand. Habib and Sarkar [43] formulated a supply chain model based on fuzzy possibilistic optimization and multi-criteria of decision-making strategy. Giri et al. [44] discussed an SCM model same as previous, but they introduced closed-loop SCM for green products. Their model introduced a revenue-sharing strategy with green-sensitive customer demand.

The author's contribution in Table 1 describes at a glance the different research gaps mentioned in the literature review portion. From this table, it is clear that research on selling price and energy consumption based demand has not been seen yet. Besides, 
the consideration of the preventive maintenance policy and restoration investment for the out-of-control situation has been bought the system under control for a variable production rate, which has not been seen in previous research. Moreover, the table has helped us to highlight all these research gaps.

The rest of this paper is such that. Section 3 presents the purpose of the problem, related mathematical symbols, and associated hypotheses. The mathematical modeling is presented in Section 4. Section 5 provides the methodology to determine the solution. Numerical applications are described in Section 6. Section 7 presents a sensitivity analysis. Section 8 presents the managerial insights of this study, and Section 9 presents the conclusions.

Table 1. Contribution of the previous authors.

\begin{tabular}{|c|c|c|c|c|c|c|c|c|c|}
\hline Author(s) & $\begin{array}{c}\text { Production } \\
\text { Rate }\end{array}$ & $\begin{array}{l}\text { Demand } \\
\text { Rate }\end{array}$ & $\begin{array}{l}\text { Defective } \\
\text { Products }\end{array}$ & $\begin{array}{l}\text { Maintenance } \\
\text { Policy }\end{array}$ & Backorder & Rework & Warranty & $\begin{array}{c}\text { Energy } \\
\text { Consumption }\end{array}$ & $\begin{array}{l}\text { Model } \\
\text { Type }\end{array}$ \\
\hline Cárdenas-Barrón [3] & Constant & Fixed & - & - & - & Yes & - & - & Inventory \\
\hline Nakagawa [6] & Constant & Constant & Yes & Yes & - & Yes & - & - & Inventory \\
\hline Sana [7] & Variable & Fixed & Yes & - & - & Yes & Yes & - & Inventory \\
\hline Khanna et al. [8] & Constant & Fixed & Yes & Yes & Planned & Yes & Yes & - & SCM \\
\hline Sana [9] & Constant & Fixed & Yes & Yes & - & Yes & Yes & - & Inventory \\
\hline Khan et al. [10] & Constant & Average & Yes & - & - & - & - & Yes & SCM \\
\hline Bhuniya et al. [11] & Variable & SPADD & - & - & - & Yes & - & Yes & Inventory \\
\hline Dey et al. [12] & Variable & SPQDD & - & - & Planned & - & - & - & $\begin{array}{l}\text { Single } \\
\text { stage }\end{array}$ \\
\hline Hsu \& Hsu [16] & Constant & Fixed & Yes & - & Planned & - & - & - & Integrated \\
\hline Liu et al. [21] & Constant & Fixed & - & Yes & - & - & - & - & Inventory \\
\hline Kim et al. [24] & Constant & Average & Yes & - & Planned & - & - & - & Inventory \\
\hline Taleizadeh et al. [26] & Constant & Fixed & Yes & - & Partial & Yes & - & - & EPQ \\
\hline Guchhait et al. [27] & Constant & Fixed & Yes & - & Planned & Yes & Yes & - & Inventory \\
\hline Mishra et al. [28] & Constant & Fixed & - & - & - & Yes & - & - & EOQ \\
\hline Chang et al. [30] & Variable & Fixed & Yes & - & Planned & Yes & - & - & EMQ \\
\hline Alduragam et al. [32] & Variable & Stochastic & - & - & - & - & - & - & Integrated \\
\hline Majumder et al. [33] & Variable & Average & - & - & Partial & - & - & - & SCM \\
\hline Wu et al. [35] & Constant & $\begin{array}{c}\text { Stock } \\
\text { dependent }\end{array}$ & - & - & Partial & - & - & - & Inventory \\
\hline Meng et al. [38] & Constant & Fixed & - & - & - & - & - & Yes & SCM \\
\hline Rad et al. [42] & Constant & SPD & Yes & - & Planned & - & - & - & SCM \\
\hline Giri et al. [44] & Constant & SPWDD & - & - & - & - & Yes & - & SCM \\
\hline This paper & Variable & SPECDD & Yes & Yes & Planned & Yes & Yes & Yes & SCM \\
\hline
\end{tabular}

SCM-“Supply chain management", EPQ-“Economic production quantity", EMQ-“Economic manufacturing quantity”, SPECD-“Selling price and energy consumption dependent demand", SPADD-"Selling price and advertisement dependent demand", SPQDD-“Selling price and quality dependent demand", SPD-"Selling price dependent", SPWGDD-"Selling price, warranty dependent demand".

\section{Problem Purpose, Symbols, and Hypotheses}

Here, the purpose of the problem with symbols and hypotheses are adequately described. At first, the problem purpose is described elaborately, then symbols of the mathematical model, and at the last portion, assuming hypotheses describe.

\subsection{Problem Purpose}

This study proposes a suitable way of smart production, and through SCM, it delivers to the customer's hand. Here, selling price and energy consumption dependent demand are considered for the producer and customer benefit. This idea is especially significant in that case. The production process, considered here, may be disrupted due to the out-ofcontrol situation. Two-way costs have been used to overcome this barrier, viz, restoration cost during the production run time, and maintenance policy during the non-production time. Through all these, the two supply chain members, the manufacturer and the retailer 
have different needs in mind. The plan to increase profits has been made in the model. Manufacturer's production and a parallel rework of defective products are some of the features of this model. The warranty policy is a way to increase the popularity of products. The proposed model is an extended model of the Khanna et al. [8] by considering variable production rate and variable demand with the maximum profit. The main focus of this model is energy-dependent demand. Customers use such a company's smart products that have low energy consumption. Automatically, the demand gradually increases with this matter. Besides, another thing is that the price of the smart product. Here, the Figure 1. presents a model structure of a smart production process under the SCM. The manufacturer first produces products through the smart production process. Among the produced products, perfect quality products are sent to the retailer, and the defective products are reworked, and after making them perfect, there are sent to the retailer for sale. Each product has a specific warranty period on it. The preventive maintenance cost is invested as a regular checking cost to stop machine breakdown. However, if the machine break down occurs, the restoration cost is invested in recovering it, in restoring the machine in its previous good state. Besides, this study considers different examples to show the model's robustness. The proposed model considers a lot size quantity, backorder quantity, the number of shipments from the manufacturer to the retailer, the selling price, and the variable production rate as the decision variables. The optimal values of the decision variables and the total expected profit are proved here numerically and analytically. The classical optimization technique helps to detect the optimum values of decision variables and the total expected profit.

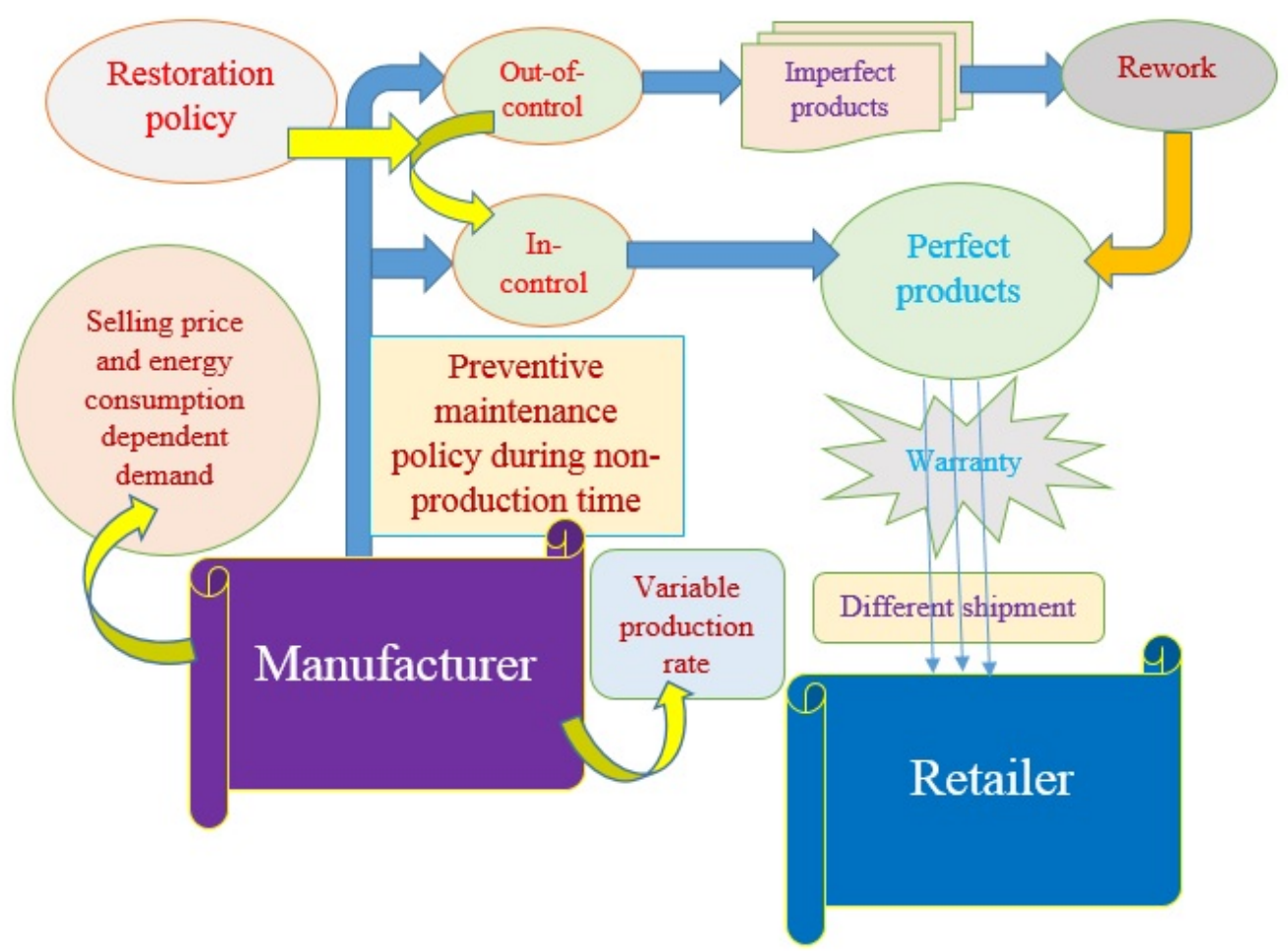

Figure 1. The model structure of proposed supply chain management.

3.2. Notation and Assumptions

3.2.1. Notation

The following notation is considered for the model.

\section{Decision variables}

$P \quad$ production rate (unit/year)

$\zeta \quad$ shipment size (units/year) 


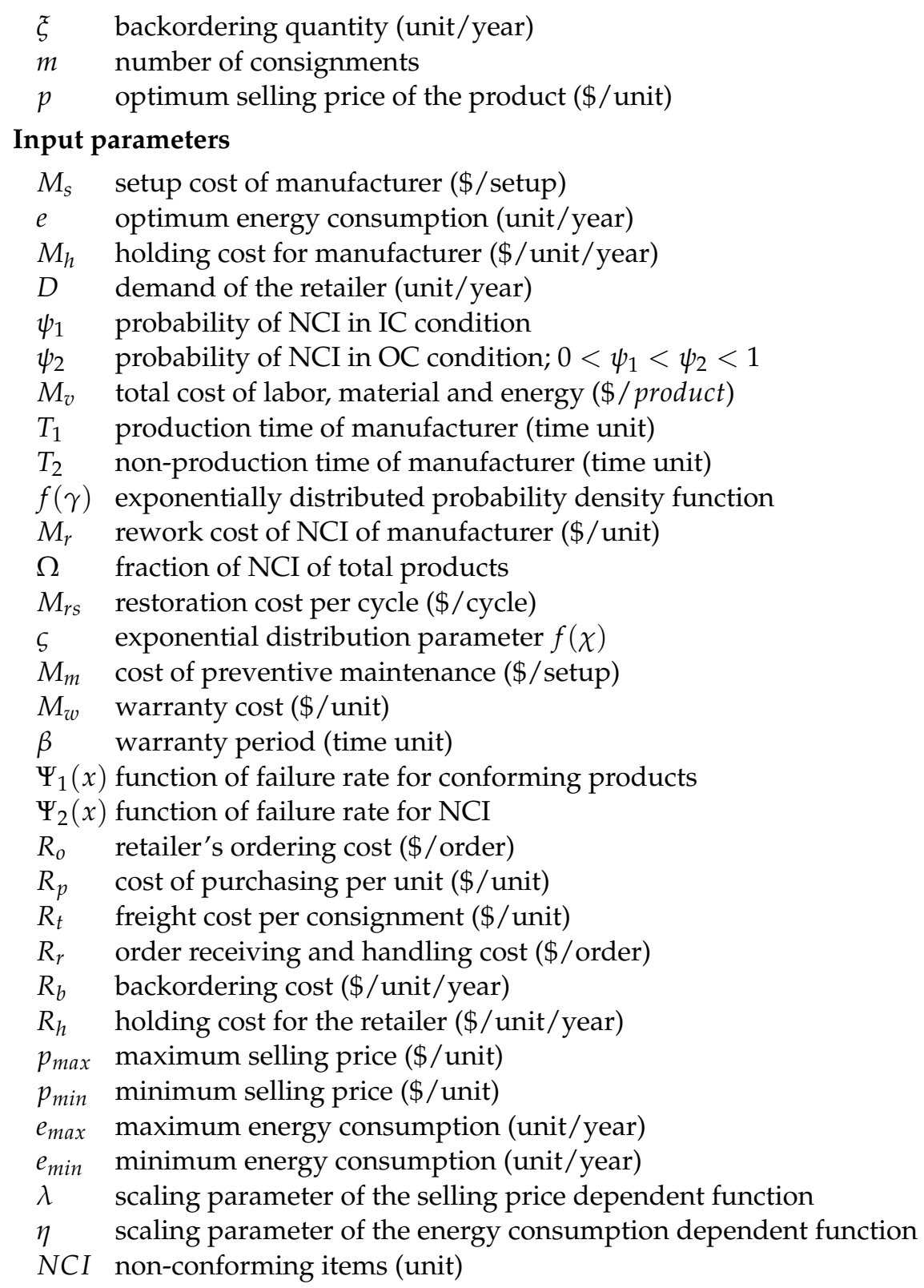

\subsubsection{Assumptions}

1 The demand is considered to be selling price and renewable energy dependent. It is taken as $D=\lambda \frac{\left(p_{\max }-p\right)}{\left(p-p_{\min }\right)}+\eta \frac{\left(e_{\max }-e\right)}{\left(e-e_{\min }\right)}$, where $\lambda$ and $\eta$ are the scaling parameters.

2 This SCM model considers a single-manufacturer and single-retailer. Shortages are fully backlogged, as the production rate is considered as variable, the production rate is greater than demand.

3 This model considers an imperfect production, which may be occurred after out-ofcontrol situation of the production system. To prevent this type of out-of-situation, the preventive maintenance policy and restoration technique are considered during the non production time. (See Khanna et al. [8])

4 The defective or NCI are reworked parallel with the manufacturing. Another facility is provided as free minimal repair warranty of the defective products. (See Guchhait et al. [27])

5 For conforming products and NCI, the function of failure rate be as $\Psi_{1}(x)=\omega_{1}^{\varphi_{1}} \varphi_{1} x^{\varphi_{1}-1}$ and $\Psi_{2}(x)=\omega_{2}^{\varphi_{2}} \varphi_{2} x^{\varphi_{2}-1}$ (See Sana [7]) 
6 The probability density function of $\gamma$ and $T_{2}$ be such that $f(\gamma)=0.5^{-0.5 \gamma}$ and $f\left(T_{2}\right)=$ $0.7^{-0.5 T_{2}}$, respectively. (See Khanna et al. [8]).

\section{Mathematical Model}

The supply chain is an important platform to deliver daily life necessities in the current abnormal situation. Moreover, in the current situation, a smart product is essential, becoming a step holder and carrier in every step of the typical career. With a healthy initiative, smart products have become a tool to make people's lives smarter and more advanced. This model is a time-honored approach. In this model, a smart product is produced and used to make the product available to the user only. The demand for the product depends on the selling price and energy consumption because customers want to use smart products with minimum energy consumption. Here, the retailer orders $m \zeta$ number of smart products from the manufacturer. The manufacturer produces the products during the time $T_{1}$ and delivers them the good quality products with different shipment. The model is discussed in detail in the following section.

\subsection{Manufacturer's Model}

The manufacturer produces and sells products according to retail orders in different steps. The manufacturer considers an equal time gap among different shipments. The manufacturer considers $m$ shipments with time gap T. Thus, the total time of shipments is $m T$. This time divides into two slot $T_{1}$ and $T_{2}$. In the first slot, the manufacturer produces the products, and in the second slot, the preventive maintenance policy applies to reduce the out-of-control situation. The first slot is the production time, and the second is known as non-production time. The considerable shortages are completely backlogged. The different costs related to the manufacturer are described in detail in the following section.

\subsubsection{Setup Cost (MSC)}

Such costs are considered for the mechanical infrastructure and necessary management for the smart production of smart products. Investing one time, the manufacturer can get the output over the whole cycle time. It is one of the elementary costs for production. Depending on the developed setup, the production process of the manufacturer can improve so quickly. The considerable setup cost is

$$
M S C=M_{s} .
$$

\subsubsection{Variable Cost (MVC)}

It covers various costs such as energy, labor, and raw materials during the production time $T_{1}$. These types of costs are essential for the smooth running of the production process. Besides, smart products' demand is positively related to various matters such as energy consumption, new feature, and new model type. The considerable variable cost be as

$$
M V C=M_{\mathcal{V}} P T_{1} .
$$

\subsubsection{Holding Cost (MHC)}

After the production of smart products, there are different shipments for delivering products to the retailer. Some facility of storage is needed to hold the excellent quality and defective quality products. Careful storage and maintenance of smart products after production and before deliveries are essential. The collection of defective products for rework and warranty facility needs such a holding area. Here, the considerable holding cost is as (from Khanna et al. [8])

$$
M H C=M_{h}\left(\frac{m \zeta^{2}}{P}-\frac{m^{2} \zeta^{2}}{2 P}+\frac{m(m-1) \zeta^{2}}{2 D}\right) .
$$




\subsubsection{Rework Cost (MRC)}

It is the highest prioritized cost from the manufacturer's side. During the production time $T_{1}$, the manufacturer produces smart products to control the market demand, and during the non-production time $T_{2}$, the preventive maintenance policy applies to repair the machine. Here, $f\left(T_{2}\right)$ is the density function of the random variable $T_{2}$. There is another chance of out-of-control situation of the production machine. This situation may be within $T_{1}$ or during $T_{2}$. It is assumed that after time $\gamma$, the out-of-control situation occurs. $f(\gamma)$ is a probability density function of the random time variable $\gamma$. Hence, if $\gamma \geq T_{1}$ then $\mathrm{NCI}$ is $\psi_{1} P T_{1}$ and if $\gamma<T_{1}$ then NCI is $\psi_{1} P \gamma+\psi_{2} P\left(T_{1}-\gamma\right)$. Then the expected value of the NCI is $E[N C I]=\psi_{1} P T_{1} \int_{T_{1}}^{\infty} f(\gamma) d \gamma+\psi_{1} P \int_{0}^{T_{1}} \gamma f(\gamma) d \gamma+\psi_{2} P \int_{0}^{T_{1}}\left(T_{1}-\gamma\right) f(\gamma) d \gamma$. After simplification, this reduces to $E[N C I]=\psi P T_{1}+\left(\psi_{2}-\psi_{1}\right) P \int_{0}^{T_{1}}\left(T_{1}-\gamma\right) f(\gamma) d \gamma$.

Thus, the fraction of NCI of the total manufactured products is

$$
\Omega=\frac{E[N C I]}{P T_{1}}=\psi_{1}+\frac{\left(\psi_{2}-\psi_{1}\right)}{T_{1}} \int_{0}^{T_{1}}\left(T_{1}-\gamma\right) f(\gamma) d \gamma .
$$

Hence, the rework cost is

$$
M_{r} \Omega P T_{1}=M_{r}\left(\psi_{1}+\frac{\left(\psi_{2}-\psi_{1}\right)}{T_{1}} \int_{0}^{T_{1}}\left(T_{1}-\gamma\right) f(\gamma) d \gamma\right) P T_{1} .
$$

\subsubsection{Restoration Cost (MRSC)}

It is a very necessary cost for recovery of the production system from the out-ofcontrol situation, if any. If the out-of-control situation occurs during the production time $T_{1}$, then only such restoration cost will be considered. With this investment, the manufacturer can control the machine breakdown as quickly as possible for a smooth production system. Here, the considerable restoration cost is calculated as

$$
M R S C=M_{r s} P\left(\gamma<T_{1}\right)=M_{r s}\left(1-e^{-\varsigma T_{1}}\right) .
$$

\subsubsection{Preventive Maintenance Cost (MPMC)}

A maintenance policy is one of the best strategies to control the production system and related equipment. It may be during production or during the lead time of the shifting gap. The considerable maintenance is preventive maintenance, which is applying during the non-production time. It is performed while the equipment is still working so that it does not break down unexpectedly. The considerable preventive maintenance cost be calculated as

$$
M P M C=M_{m} \int_{0}^{\infty} T_{2} f\left(T_{2}\right) d T_{2}=M_{m} E\left[T_{2}\right] .
$$

\subsubsection{Warranty Cost (MWC)}

Nowadays, the smart manufacturing system delivers such a policy for customer satisfaction and increases its popularity. The manufacturer gives a facility of free minimal repair within a certain period, known as the warranty period. Therefore, within the warranty period $[0, \beta]$, the probability of products become faulty is $(1-\Omega) \int_{0}^{\beta} \Psi_{1}(x) d x+$ $\Omega \int_{0}^{\beta} \Psi_{2}(x) d x$, where $\Psi_{1}(x)$ and $\Psi_{2}(x)$ are the failure rate function of conforming and non-conforming products, respectively. Then the warranty cost is

$$
M W C=M_{w} P T_{1}\left[(1-\Omega) \int_{0}^{\beta} \Psi_{1}(x) d x+\Omega \int_{0}^{\beta} \Psi_{2}(x) d x\right] .
$$




\subsubsection{Manufacturer's Total Cost (MTC)}

Hence, the manufacturer's total cost is as follows:

$$
\begin{aligned}
M T C & =(M S C+M V C+M H C+M R C+M R S C+M P M C+M W C) \\
& =M_{s}+M_{v} P T_{1}+M_{h}\left(\frac{m \zeta^{2}}{P}-\frac{m^{2} \zeta^{2}}{2 P}+\frac{m(m-1) \zeta^{2}}{2 D}\right) \\
& +M_{r}\left(\psi_{1}+\frac{\left(\psi_{2}-\psi_{1}\right)}{T_{1}} \int_{0}^{T_{1}}\left(T_{1}-\gamma\right) f(\gamma) d \gamma\right) P T_{1}+M_{r s}\left(1-e^{-\varsigma T_{1}}\right) \\
& +M_{m} \int_{0}^{\infty} T_{2} f\left(T_{2}\right) d T_{2}+M_{w} P T_{1}\left[(1-\Omega) \int_{0}^{\beta} \Psi_{1}(x) d x+\Omega \int_{0}^{\beta} \Psi_{2}(x) d x\right] .
\end{aligned}
$$

\subsection{Retailer's Model}

The retailer is another essential member of the supply chain through whom the smart products are delivered to the customers' hands. The time interval $T$ (time gap between two successive shipments from the manufacturer to the retailer) is divided into two-time slots $T^{\prime}$ and $T^{\prime \prime}$. In the time $T^{\prime}$, the inventory reduces because of customers' demand. During the time $T^{\prime \prime}$, the shortages occur but assume that the shortages are fully backlogged. The description of different costs related to the retailer's site is described in the following section.

\subsubsection{Ordering Cost (ROC)}

Ordering cost is the most significant cost related to the SCM, by which the retailer can order the desired demand to the manufacturer. To purchase the products from the manufacturer, the retailer invests such a cost called ordering cost. It may be in a different method such as phone call, mail, sending a representative, or any other ordering method. Hence, the total ordering cost of the retailer is

$$
R O C=R_{o} .
$$

\subsubsection{Purchasing Cost (RPC)}

This type of cost is paid by the retailer to the manufacturer when products are delivered to the retailer. To continue the smooth running business, the manufacturer needs such cost for the necessary department's payment. Hence this type of cost is as follows:

$$
R P C=R_{p} m \zeta .
$$

\subsubsection{Shipment Cost (RSC)}

The retailer bears this cost to receive different shipments from the manufacturer according to the products' order. If $R_{t}$ be the freight cost per consignment then the transportation cost for $m$ shipment is $m R_{t}$. If $R_{r}$ be the receiving and handling cost per unit, then the handling cost for $m \zeta$ amount of products is $R_{r} m \zeta$. Hence, the sum of the transportation and handling cost is called here as shipment cost, which is as follows:

$$
R S C=\left(m R_{t}+R_{r} m \zeta\right) .
$$

\subsubsection{Backordering Cost (RBC)}

Backorder is a most sensitive matter in the recent competitive market of smart products. Customers can not wait long for the absence of the products in the retailing shop. Backorder is of two types, full and partial backorder. If the customer can wait for the delay for the delivery, it becomes a partial backorder. Otherwise, it is known as a full backorder when the customer cannot wait for the delay. However, backorder can destroy the good relationship between the manufacturer and the retailer. Here a planned backorder cost is included 
to control the market demand, i.e., it is assumed that shortages are fully backlogging. This type of cost is

$$
R B C=\frac{R_{b} m \xi^{2}}{2 D}
$$

\subsubsection{Holding Cost (RHC)}

The retailer receives the products from the manufacturer and stocks them in the warehouse or stock room using this cost. After receiving the products, these may sell immediately or may stock for some more time. Depending on the backorder products, the holding cost is calculated based on the remaining inventory. Here, the retailer receives $\zeta$ products, and $\xi$ be the backorder product. Thus the remaining product $(\zeta-\xi)$ has to hold for the retailer. The average inventory level is $\frac{1}{2}(\zeta-\xi)$, and $T^{\prime}=\frac{(\zeta-\xi)}{D}, T=\frac{\zeta}{D}$. Then the holding cost of the retailer is

$$
R H C=\frac{R_{h} m(\zeta-\xi)^{2}}{2 D} .
$$

\subsubsection{Retailer Total Cost (RTC)}

Hence, the total cost of the retailer be such as follows:

$$
\begin{aligned}
R T C & =(R O C+R P C+R S C+R B C+R H C) \\
& =R_{o}+R_{p} m \zeta+\left(m R_{t}+R_{r} m \zeta\right)+\frac{R_{b} m \xi^{2}}{2 D}+\frac{R_{h} m(\zeta-\xi)^{2}}{2 D} .
\end{aligned}
$$

\subsection{Joint Total Cost (JTC)}

Hence, the manufacturer and retailer's joint total cost are obtained by adding their corresponding costs, which is as follows:

$$
\begin{aligned}
J T C & =M T C+R T C \\
& =M_{s}+M_{v} P T_{1}+M_{h}\left(\frac{m \zeta^{2}}{P}-\frac{m^{2} \zeta^{2}}{2 P}+\frac{m(m-1) \zeta^{2}}{2 D}\right) \\
& +M_{r}\left(\psi_{1}+\frac{\left(\psi_{2}-\psi_{1}\right)}{T_{1}} \int_{0}^{T_{1}}\left(T_{1}-\gamma\right) f(\gamma) d \gamma\right) P T_{1}+M_{r s}\left(1-e^{-\varsigma T_{1}}\right) \\
& +M_{m} \int_{0}^{\infty} T_{2} f\left(T_{2}\right) d T_{2}+M_{w} P T_{1}\left[(1-\Omega) \int_{0}^{\beta} \Psi_{1}(x) d x+\Omega \int_{0}^{\beta} \Psi_{2}(x) d x\right] \\
& +R_{o}+R_{p} m \zeta+\left(m R_{t}+R_{r} m \zeta\right)+\frac{R_{b} m \xi^{2}}{2 D}+\frac{R_{h} m(\zeta-\xi)^{2}}{2 D} .
\end{aligned}
$$

If the two members of the SCM, manufacturer, and retailer work together in a coordinated way to minimize the JTC and maximize the Total Expected Profit (TEP). Then the JTC of the manufacturer and retailer is reducing as

$$
\begin{aligned}
& \operatorname{JTC}(P, \zeta, m, \eta, \xi)=\frac{\left(\lambda \frac{\left(p_{\max }-p\right)}{\left(p-p_{\min }\right)}+\eta \frac{\left(e_{\max }-e\right)}{\left(e-e_{\min }\right)}\right)}{m \zeta}\left[M_{s}+M_{v} P T_{1}+M_{h}\left(\frac{m \zeta^{2}}{P}-\frac{m^{2} \zeta^{2}}{2 P}+\frac{m(m-1) \zeta^{2}}{2 D}\right)\right. \\
& +M_{r}\left(\psi_{1}+\frac{\left(\psi_{2}-\psi_{1}\right)}{T_{1}} \int_{0}^{T_{1}}\left(T_{1}-\gamma\right) f(\gamma) d \gamma\right) P T_{1}+M_{r s}\left(1-e^{-\varsigma T_{1}}\right) \\
& +\quad M_{m} \int_{0}^{\infty} T_{2} f\left(T_{2}\right) d T_{2}+M_{w} P T_{1}\left((1-\Omega) \int_{0}^{\beta} \Psi_{1}(x) d x+\Omega \int_{0}^{\beta} \Psi_{2}(x) d x\right) \\
& \left.+\quad R_{o}+R_{p} m \zeta+\left(m R_{t}+R_{r} m \zeta\right)+\frac{R_{b} m \xi^{2}}{2 D}+\frac{R_{h} m(\zeta-\xi)^{2}}{2 D}\right], \\
& \text { where } T_{\text {cye }}=\frac{m \zeta}{D} \text { i.e., } \frac{1}{T_{\text {cye }}}=\frac{\left(\lambda \frac{\left(p_{\max }-p\right)}{\left(p-p_{\min }\right)}+\eta \frac{\left(e_{\max }-e\right)}{\left(e-e_{\min }\right)}\right)}{m \zeta} \text {. }
\end{aligned}
$$




\subsection{Total Expected Profit (TEP)}

Here revenue $=p D$ and hence the total expected profit $=$ (revenue - total cost). Therefore

$$
\begin{aligned}
T E P & =\left(\lambda \frac{\left(p_{\max }-p\right)}{\left(p-p_{\min }\right)}+\eta \frac{\left(e_{\max }-e\right)}{\left(e-e_{\min }\right)}\right)\left[p-\frac{1}{m \zeta}\left\{M_{s}+M_{v} P T_{1}+M_{h}\left(\frac{m \zeta^{2}}{P}-\frac{m^{2} \zeta^{2}}{2 P}+\frac{m(m-1) \zeta^{2}}{2 D}\right)\right.\right. \\
& +M_{r}\left(\psi_{1}+\frac{\left(\psi_{2}-\psi_{1}\right)}{T_{1}} \int_{0}^{T_{1}}\left(T_{1}-\gamma\right) f(\gamma) d \gamma\right) P T_{1}+M_{r s}\left(1-e^{-\zeta T_{1}}\right) \\
& +M_{m} \int_{0}^{\infty} T_{2} f\left(T_{2}\right) d T_{2}+M_{w} P T_{1}\left((1-\Omega) \int_{0}^{\beta} \Psi_{1}(x) d x+\Omega \int_{0}^{\beta} \Psi_{2}(x) d x\right) \\
& \left.\left.+R_{o}+R_{p} m \zeta+\left(m R_{t}+R_{r} m \zeta\right)+\frac{R_{b} m \xi^{2}}{2 D}+\frac{R_{h} m(\zeta-\xi)^{2}}{2 D}\right\}\right]
\end{aligned}
$$

where $\Psi_{1}(x)=\omega_{1}^{\varphi_{1}} \varphi_{1} x^{\varphi_{1}-1}, \Psi_{2}(x)=\omega_{2}^{\varphi_{2}} \varphi_{2} x^{\varphi_{2}-1}$ and $f(y)=\varrho e^{-\varrho y}, f(\gamma)=0.5 e^{-0.5 \gamma}$ and $T E P=\operatorname{TEP}(P, \zeta, \xi, m, p)$.

After simplification, the above equation reduces to

$$
\begin{aligned}
T E P & =\left(\lambda \frac{\left(p_{\max }-p\right)}{\left(p-p_{\min }\right)}+\eta \frac{\left(e_{\max }-e\right)}{\left(e-e_{\min }\right)}\right)\left[p-\frac{1}{m \zeta}\left\{M_{S}+M_{v} m \zeta+M_{h}\left(\frac{m \zeta^{2}}{P}-\frac{m^{2} \zeta^{2}}{2 P}+\frac{m(m-1) \zeta^{2}}{2 D}\right)\right.\right. \\
& +M_{r}\left\{\psi_{1}+\left(\psi_{2}-\psi_{1}\right)\left(1+\frac{2 P}{m \zeta}\left(e^{\frac{-m \zeta}{2 P}}-1\right)\right)\right\} m \zeta+M_{r s}\left(1-e^{-\zeta \frac{m \zeta}{P}}\right)+M_{m} \int_{0}^{\infty} T_{2} f\left(T_{2}\right) d T_{2} \\
& +M_{w} m \zeta\left\{\omega_{1}^{\varphi_{1}} \beta^{\varphi_{1}}+\left(\omega_{2}^{\varphi_{2}} \beta^{\varphi_{2}}-\omega_{1}^{\varphi_{1}} \beta^{\varphi_{1}}\right)\left\{\psi_{1}+\left(\psi_{2}-\psi_{1}\right)\left(1+\frac{2 P}{m \zeta}\left(e^{\frac{-m \zeta}{2 P}}-1\right)\right)\right\}\right\} \\
& \left.\left.+R_{o}+R_{p} m \zeta+\left(m R_{t}+R_{r} m \zeta\right)+\frac{R_{b} m \tilde{\zeta}^{2}}{2 D}+\frac{R_{h} m(\zeta-\xi)^{2}}{2 D}\right\}\right] .
\end{aligned}
$$

\section{Solution Methodology}

Here, to solve the mathematical model, the classical optimization method is considered analytically and numerically also. The decision variable $m$ is optimized using a discrete optimization technique. As there are multiple decision variables, the Hessian matrix is used to test the solution's globality. The total expected profit is partially differentiated concerning the decision making variables and equated to zero. Thus, optimum values of the decision variables $P^{*}, p^{*}, \zeta^{*}, \zeta^{*}$ such as follows:

The optimal values of the decisions variable are

$$
\begin{aligned}
P^{*} & =\frac{1}{2(\theta+\phi)}\left[\frac{m \zeta}{2}(\theta+\phi)+M_{h} \zeta^{2}\left(m-\frac{m^{2}}{2}\right)-M_{r s} m \zeta \zeta e^{-\varsigma T_{1}}\right] \\
p^{*} & =p_{\text {min }}+\sqrt{\frac{\lambda \vartheta}{D}\left(p_{\max }-p_{\text {min }}\right)} \\
\zeta^{*} & =\frac{-\omega+\sqrt{\omega^{2}+4(J T C)\left[2 M_{h}\left(\frac{m}{P}-\frac{m^{2}}{2 P}+\frac{m(m-1)}{2 D}\right)+\frac{R_{h} m}{D}\right]}}{\zeta\left[2 M_{h}\left(\frac{m}{P}-\frac{m^{2}}{2 P}+\frac{m(m-1)}{2 D}\right)+\frac{R_{h} m}{D}\right]} \\
\xi^{*} & =\frac{R_{h} \zeta}{\left(R_{b}+R_{h}\right)^{\prime}}
\end{aligned}
$$

where

$$
\begin{aligned}
\theta & =M_{r} m \zeta\left(\psi_{2}-\psi_{1}\right) \\
\phi & =M_{w} m \zeta\left(\psi_{2}-\psi_{1}\right)\left(\omega_{2}^{\varphi_{2}} \beta^{\varphi_{2}}-\omega_{1}^{\varphi_{1}} \beta^{\varphi_{1}}\right) \\
\vartheta & =(p-J T C)+\frac{M_{h}}{m D}(m-1) \zeta+\left(\frac{R_{b} m \xi^{2}}{2 D}+\frac{R_{h} m(\zeta-\xi)^{2}}{2 D}\right)
\end{aligned}
$$




$$
\begin{aligned}
\omega & =\left[M_{v} m+M_{r}\left\{\psi_{1}+\left(\psi_{2}-\psi_{1}\right)\left(1+\frac{2 P}{m \zeta}\left(e^{\frac{-m \zeta}{2 P}}-1\right)\right)\right\} m+M_{r s} \frac{\zeta m}{P} e^{-\frac{\zeta m \zeta}{P}}\right. \\
& +M_{w} m\left\{\omega_{1}^{\varphi_{1}} \beta^{\varphi_{1}}+\left(\omega_{2}^{\varphi_{2}} \beta^{\varphi_{2}}-\omega_{1}^{\varphi_{1}} \beta^{\varphi_{1}}\right)\left\{\psi_{1}+\left(\psi_{2}-\psi_{1}\right)\left(1+\frac{2 P}{m \zeta}\left(e^{\frac{-m \zeta}{2 P}}-1\right)\right)\right\}\right\} \\
& \left.-(\theta+\phi)\left\{\frac{2 P}{m \zeta^{2}}\left(e^{-\frac{m \zeta}{2 P}}-1\right)-\frac{1}{\zeta} e^{-\frac{m \zeta}{2 P}}\right\}+m\left(R_{r}+R_{p}\right)-\frac{R_{h} m \xi}{D}\right]
\end{aligned}
$$

See Appendix ?? for the calculations of first-order derivatives.

Proposition 1. The optimum value of the variable m (number of consignments) is obtained through the satisfaction of the following inequalities

$\operatorname{TEP}(m-1) \leq \operatorname{TEP}(m) \geq \operatorname{TEP}(m+1)$

Those utilizing the proposition can be obtained by the following method. Here, the number of consignments $m^{*}$ deliveries to the retailer per production batch is an integer. Thus, it is optimized via the discrete optimization technique, and the optimal value can be determined using the necessary conditions. For the optimal total expected profit (TEP) at $\zeta=\zeta^{*}, \xi=\xi^{*}, P=P^{*}$ and $p=p^{*}$ the necessary condition is

$\operatorname{TEP}\left(\zeta^{*}, \zeta^{*}, P^{*}, m^{*}-1, p^{*}\right) \leq \operatorname{TEP}\left(\zeta^{*}, \zeta^{*}, P^{*}, m^{*}, p^{*}\right) \geq \operatorname{TEP}\left(\zeta^{*}, \zeta^{*}, P^{*}, m^{*}+1, p^{*}\right)$

The optimal value of number of shipment $m$ is driven using the following equation:

$$
\frac{\sqrt{\chi}-\sqrt{4 M_{h} \zeta^{2}\left(\frac{1}{2 D}-\frac{1}{2 P}\right)+\chi}}{2 \sqrt{\chi}} \leq m^{*} \geq \frac{\sqrt{\chi}+\sqrt{4 M_{h} \zeta^{2}\left(\frac{1}{2 D}-\frac{1}{2 P}\right)+\chi}}{2 \sqrt{\chi}}
$$

where $\chi=\left[M_{s}+M_{r s}\left(1-e^{-\varsigma T_{1}}\right)+M_{m} \int_{0}^{\infty} T_{2} f\left(T_{2}\right) d T_{2}+R_{o}\right]$.

Here, sufficient condition for optimum results is shown through the classical optimization technique. A mixed-integer programming problem is used (see Appendix ??).

Proposition 2. The total expected profit function is a convex at $P^{*}, p^{*}, \zeta^{*}, \zeta^{*}$ if

$\Phi_{1}<0$

$\Phi_{1} \Phi_{2}>\Phi_{5}^{2}$

$\Phi_{1}\left(\Phi_{2} \Phi_{3}-\Phi_{7}^{2}\right)+\Phi_{6}\left(\Phi_{5} \Phi_{7}-\Phi_{6} \Phi_{2}\right)<\Phi_{5}\left(\Phi_{5} \Phi_{3}-\Phi_{6} \Phi_{7}\right)$

$\Phi_{8}^{2}\left(\Phi_{5}^{2}-\Phi_{1} \Phi_{2}\right)+\Phi_{4} \Phi_{1}\left(\Phi_{2} \Phi_{3}-\Phi_{7}^{2}\right)+\Phi_{6} \Phi_{4}\left(\Phi_{5} \Phi_{7}-\Phi_{6} \Phi_{2}\right)>\Phi_{5} \Phi_{4}\left(\Phi_{5} \Phi_{3}-\Phi_{6} \Phi_{7}\right)$

Proof. see Appendix ??.

\section{Numerical Examples}

Four examples are provided here for the numerical application to validate the model.

Example 1. The mathematical model is tested numerically to validate the theoretical solution. The supporting modified data is taken from Khanna et al. [8]. Hence $M_{s}=300$ (\$/setup); $M_{h}=1.5$ (\$/unit/year); $M_{v}=3$ (\$/unit); $M_{r}=3$ (\$/unit); $M_{r s}=150$ (\$/cycle); $M_{m}=100$ (\$/setup); $M_{w}=0.2$ (\$/unit); $\beta=2$ (time unit) $\psi_{1}=0.05 ; \psi_{2}=0.09 ; \varsigma=1.1 ; R_{o}=100$ (\$/order); $R_{p}=10$ (\$/unit); $R_{t}=25$ (\$/unit); $R_{r}=1$ (\$/order); $R_{b}=7$ (\$/unit/year); $R_{h}=2.5$ (\$/unit/year); $\lambda=10 ;$ $p_{\max }=400$ (\$/unit); $p_{\min }=300$ (\$/unit); $\eta=50 ; e_{\max }=220$ (unit/year); $e_{\min }=110$ (unit/year); $e=150$ (unit/year); $\omega_{1}=0.028 ; \omega_{2}=0.083 ; \varphi_{1}=2 ; \varphi_{2}=2$.

Table 2 gives optimal solutions of different decision variables and $*$ denotes the optimal value. 
Table 2. Number of consignments for the optimum solution.

\begin{tabular}{cccccc}
\hline $\mathbf{m}$ & $\mathbf{P}$ & $\boldsymbol{\zeta}$ & $\boldsymbol{\xi}$ & $\mathbf{p}$ & $\begin{array}{c}\mathbf{T E P}(\mathbf{m}, \mathbf{P}, \boldsymbol{\zeta}, \\
\boldsymbol{\xi}, \mathbf{p}) \\
\mathbf{( \$ / Y e a r )}\end{array}$ \\
\hline 3 & 340.84 & 95.77 & 25.20 & 360.49 & $32,120.80$ \\
$4^{*}$ & $642.30^{*}$ & $72.11^{*}$ & $18.98^{*}$ & $360.49^{*}$ & $32,124.20^{*}$ \\
5 & 1087.67 & 58.20 & 15.31 & 360.49 & $32,121.10$ \\
6 & 1866.11 & 49.04 & 12.91 & 360.48 & $32,115.70$ \\
7 & 3657.61 & 42.55 & 11.20 & 360.48 & $32,109.40$ \\
8 & $12,634.40$ & 37.71 & 9.92 & 360.48 & $32,102.60$ \\
\hline
\end{tabular}

The optimal result of the decision variable are $P^{*}=642.30$ (units/year); $\zeta^{*}=72.11$ (units/year); $\xi^{*}=18.98$ (units/year); $p^{*}=360.49$ (\$/unit); $m=4$ and at this optimal values the total expected profit $($ TEP) $=32,124.20$ ( $\$$ /year).

The optimality of the result is checked analytically as well as numerically.

Here $H_{11}=-0.0899791<0 ; H_{22}=0.0106528>0 ; H_{33}=-0.0273082<0 ; H_{44}=5.70031$ $\times 10^{-7}>0$.

The following three-dimension Figures $2-5$ are total expected profit (TEP) versus different pair decision variables. The concavity of the figures indicated the profit of the model in different cases.

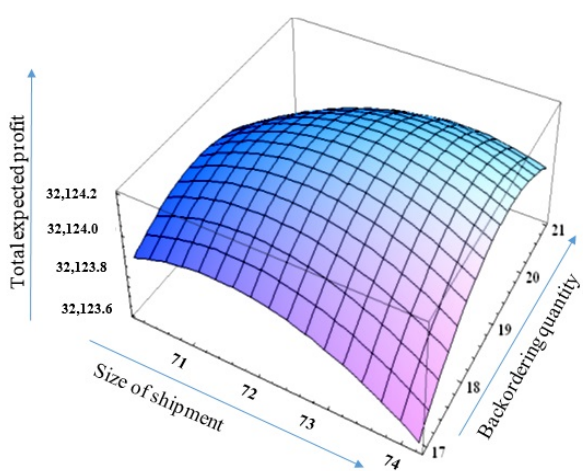

Figure 2. Total Expected Profit (TEP) versus size of shipments and backordering quantity.

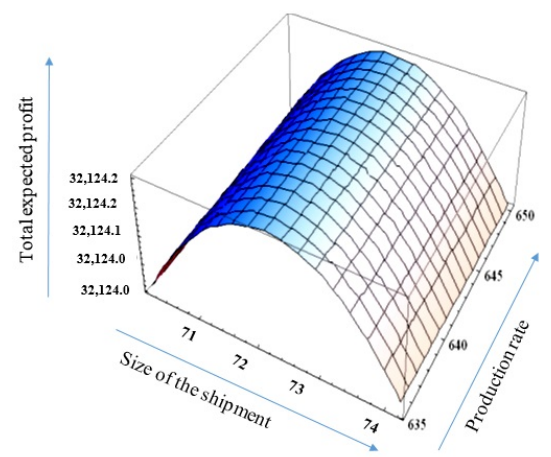

Figure 3. Total Expected Profit (TEP) versus size of shipments and production rate. 


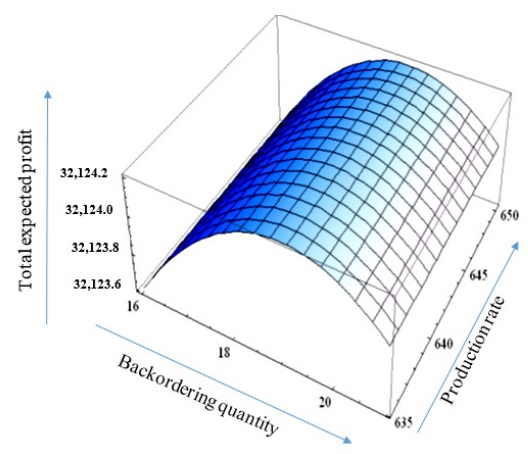

Figure 4. Total Expected Profit (TEP) versus backordering quantity and production rate.

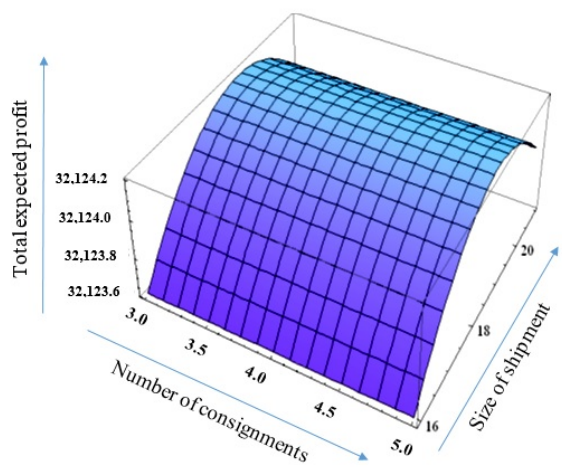

Figure 5. Total Expected Profit (TEP) versus number of consignments and size of shipments.

Example 2. The supporting data is taken from Khanna et al. [8]. Here, $M_{s}=300$ ( $\$ /$ setup); $M_{h}=1.5$ (\$/unit/year); $M_{v}=3$ (\$/unit); $M_{r}=3$ (\$/unit); $M_{r s}=150$ (\$/cycle); $M_{m}=105$ (\$/setup); $M_{w}=0.2$ (\$/unit); $\beta=2$ (time unit) $\psi_{1}=0.05 ; \psi_{2}=0.09 ; \varsigma=40.1 ; R_{o}=100$ (\$/order); $R_{p}=10$ (\$/unit); $R_{t}=27$ (\$/unit); $R_{r}=1$ (\$/order); $R_{b}=8$ (\$/unit/year); $R_{h}=2.5$ (\$/unit/year); $\lambda=10 ; p_{\max }=400$ (\$/unit); $p_{\min }=300$ (\$/unit); $\eta=50 ; e_{\max }=220$ (unit/year); $e_{\min }=110$ (unit/year); $e=150$ (unit/year); $\omega_{1}=0.028 ; \omega_{2}=0.083 ; \varphi_{1}=2 ; \varphi_{2}=2$.

The optimal result of the decision variables are $P^{*}=3605.7$ (units/year); $\zeta^{*}=46.27$ (units/year); $\xi^{*}=12.18$ (units/year); $p^{*}=360.45$ (\$/unit); $m=7$ and at this optimal values, the TEP $=32,069.50$ (\$/year).

The optimality of the result is checked analytically as well as numerically.

Here $H_{11}=-0.237359<0 ; H_{22}=0.0458175>0 ; H_{33}=-0.117526<0 ; H_{44}=1.46721$ $\times 10^{-7}>0$.

Example 3. A new example is considered here. The supporting modified data is taken from Khanna et al. [8] and others data taken from industry visit. Here $M_{s}=300$ (\$/setup); $M_{h}=1.7$ (\$/unit/year); $M_{v}=3$ (\$/unit); $M_{r}=3$ (\$/unit); $M_{r s}=150$ (\$/cycle); $M_{m}=100$ (\$/setup); $M_{w}=$ 0.2 (\$/unit); $\beta=2$ (time unit) $\psi_{1}=0.05 ; \psi_{2}=0.09 ; \varsigma=40.1 ; R_{o}=100$ (\$/order); $R_{p}=12$ (\$/unit); $R_{t}=25$ (\$/unit); $R_{r}=1$ (\$/order); $R_{b}=7$ (\$/unit/year); $R_{h}=2.5$ (\$/unit/year); $\lambda=10 ; p_{\max }=$ 400 (\$/unit); $p_{\min }=300$ (\$/unit); $\eta=50 ; e_{\max }=220$ (unit/year); $e_{\min }=110$ (unit/year); $e=150$ (unit/year); $\omega_{1}=0.028 ; \omega_{2}=0.083 ; \varphi_{1}=2 ; \varphi_{2}=2$.

The optimal value of the decision variables are given as $P^{*}=3457.99$ (units/year); $\zeta^{*}=53.06$ (units/year); $\xi^{*}=13.97$ (units/year); $p^{*}=360.46$ (\$/unit); $m=6$ and at this optimal values, the TEP $=32,075.20$ (\$/year).

The values of the Hessian matrix is checked both analytically and numerically. The numerical values are $H_{11}=0.180213<0 ; H_{22}=0.03004445>0 ; H_{33}=-0.0770627<0 ; H_{44}=1.02044$ $\times 10^{-7}>0$. 
Example 4. Another example is considered here. The supporting modified data is taken from Khanna et al. [8] and others data taken from industry visit. Here, $M_{S}=300$ (\$/setup); $M_{h}=1.5$ (\$/unit/year); $M_{v}=3$ (\$/unit); $M_{r}=3$ (\$/unit); $M_{r s}=350$ (\$/cycle); $M_{m}=100$ (\$/setup); $M_{w}=$ 0.2 (\$/unit); $\beta=2$ (time unit) $\psi_{1}=0.05 ; \psi_{2}=0.09 ; \varsigma=40.1 ; R_{o}=100$ (\$/order); $R_{p}=10$ (\$/unit); $R_{t}=25$ (\$/unit); $R_{r}=1$ (\$/order); $R_{b}=7$ (\$/unit/year); $R_{h}=2.5$ (\$/unit/year); $\lambda=10 ; p_{\text {max }}=400$ (\$/unit); $p_{\min }=300$ (\$/unit); $\eta=50 ; e_{\max }=2640$ (unit/year); $e_{\min }=1320$ (unit/year); $e=1550$ (unit/year); $\omega_{1}=0.028 ; \omega_{2}=0.083 ; \varphi_{1}=2 ; \varphi_{2}=2$.

The optimum values of all decision variables are as follows: $P^{*}=4914.60$ (units/year); $\zeta^{*}=163.97$ (units/year); $\zeta^{*}=43.15$ (units/year); $p^{*}=335.39$ (\$/unit); $m=3$ and TEP is 81,196.10 (\$/year).

The values of the Hessian matrix is checked both analytically and numerically. The numerical values are $H_{11}=-0.0322799<0 ; H_{22}=0.00163777>0 ; H_{33}=-0.0210071<0 ; H_{44}=$ $2.06397 \times 10^{-8}>0$.

Table 3 compares the total expected profits (TEP) of the four given examples. There is another scope to maximize the TEP by increasing the production rate, which depends on the total cost of making the products, although backorder quantity, shipment size, and several shipments also maximize the TEP. The examples show how the total profit can be extended.

Table 3. Comparative study.

\begin{tabular}{ccccc}
\hline $\begin{array}{c}\text { Decision } \\
\text { Variables }\end{array}$ & Example 1 & Example 2 & Example 3 & Example 4 \\
\hline $\mathrm{m}$ & 4 & 7 & 6 & 3 \\
$\mathrm{P}$ (units/year) & 642.30 & 3605.7 & 3457.99 & 4914.60 \\
$\zeta$ (units/year) & 72.11 & 46.27 & 53.06 & 163.97 \\
$\xi$ (units/year) & 18.98 & 12.18 & 13.97 & 43.15 \\
$\mathrm{p}(\$ /$ unit) & 360.49 & 360.45 & 360.46 & 335.39 \\
$\mathrm{TEP}(\mathrm{m}, \mathrm{P}, \zeta, \xi$, & $32,124.20$ & $32,069.50$ & $32,075.20$ & $81,196.10$ \\
$\mathrm{p})(\$ /$ year) & & & & \\
\hline
\end{tabular}

\section{Sensitivity Analysis}

Significant observation for cost parameters are numerically calculated and the changes of these parameters are enlisted in the Table 4 and Figures 6-8. Table 4 shows how cost parameters effect the TEP due to the changes of $(-50 \%,-25 \%,+25 \%,+50 \%)$. Figure 6 shows the effects of changes in parametric values versus total expected profit for the most sensitive parameter $R_{p}$. Figure 7 shows the effects of changes in parametric values versus total expected profit for the most sensitive parameter $R_{o}$. Figure 8 shows the effects of changes in parametric values versus total expected profit for all the parameter. From the following sensitivity table,the following can be concluded. 


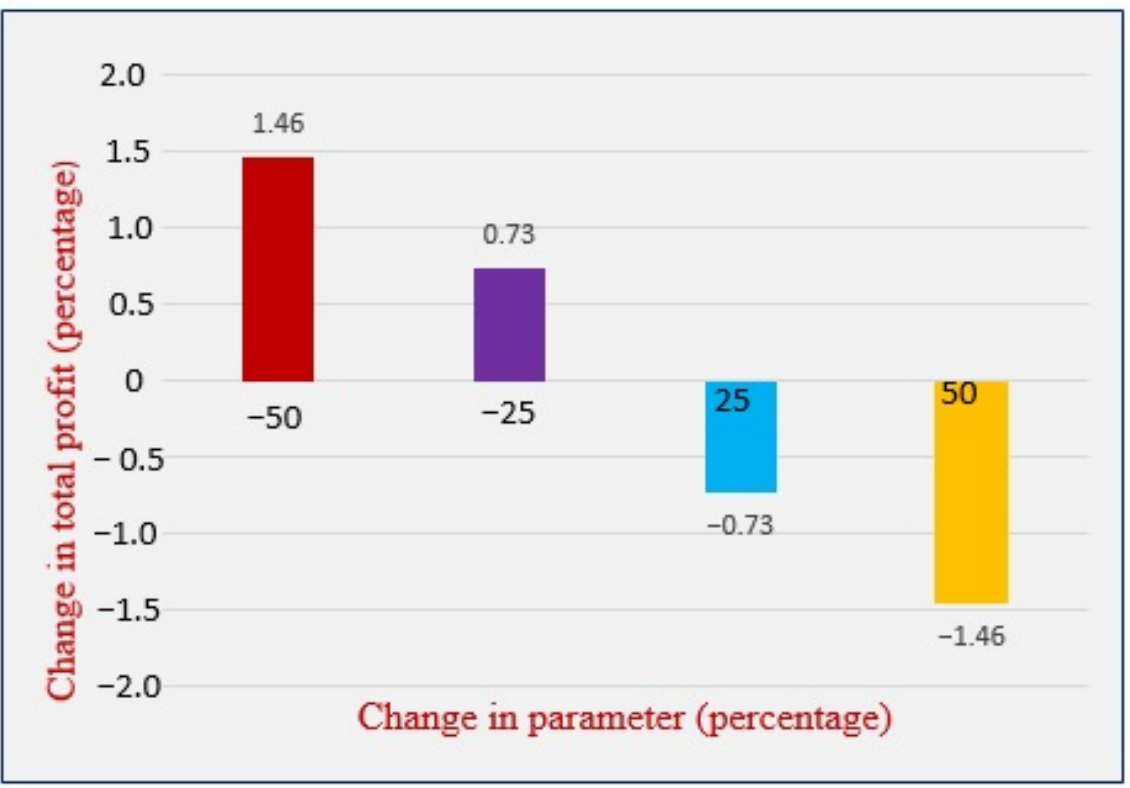

Figure 6. Effects of changes in parametric values versus total expected profit for the most sensitive parameter $R_{p}$.

Table 4. Sensitivity analysis table.

\begin{tabular}{cccccc}
\hline Parameters & Change (\%) & TEP (\%) & Parameters & Change (\%) & TEP (\%) \\
\hline \multirow{4}{*}{$M_{s}$} & $-50 \%$ & +0.16 & & $-50 \%$ & +0.05 \\
& $-25 \%$ & +0.08 & & $-25 \%$ & +0.03 \\
& $+25 \%$ & -0.08 & $R_{o}$ & $+25 \%$ & -0.03 \\
& $+50 \%$ & -0.15 & & $+50 \%$ & -0.05 \\
\hline \multirow{4}{*}{$M_{h}$} & $-50 \%$ & +0.25 & & $-50 \%$ & +1.46 \\
& $-25 \%$ & +0.12 & & $-25 \%$ & +0.73 \\
& $+25 \%$ & -0.11 & $R_{p}$ & $+25 \%$ & -0.73 \\
& $+50 \%$ & -0.21 & & $+50 \%$ & -1.46 \\
\hline \multirow{4}{*}{$M_{v}$} & $-50 \%$ & +0.44 & & $-50 \%$ & +0.05 \\
& $-25 \%$ & +0.22 & & $-25 \%$ & +0.03 \\
& $+25 \%$ & -0.22 & $R_{t}$ & $+25 \%$ & -0.03 \\
& $+50 \%$ & -0.44 & & $+50 \%$ & -0.05 \\
\hline \multirow{4}{*}{$M_{r}$} & $-50 \%$ & +0.02 & & $-50 \%$ & +0.15 \\
& $-25 \%$ & +0.01 & & $-25 \%$ & +0.08 \\
& $+25 \%$ & -0.01 & $R_{r}$ & $+25 \%$ & -0.08 \\
& $+50 \%$ & -0.02 & & $+50 \%$ & -0.15 \\
\hline \multirow{3}{*}{$M_{r s}$} & $-50 \%$ & +0.02 & & $-50 \%$ & +0.04 \\
& $-25 \%$ & +0.01 & & $-25 \%$ & +0.02 \\
& $+25 \%$ & -0.02 & $R_{b}$ & $+25 \%$ & -0.01 \\
& $+50 \%$ & -0.04 & & $+50 \%$ & -0.02 \\
\hline \multirow{3}{*}{$M_{m}$} & $-50 \%$ & +0.07 & & $-50 \%$ & +0.10 \\
& $-25 \%$ & +0.04 & & $-25 \%$ & +0.04 \\
& $+25 \%$ & -0.04 & $R_{h}$ & $+25 \%$ & -0.04 \\
& $+50 \%$ & -0.07 & & $+50 \%$ & -0.07 \\
\hline \multirow{6}{*}{} & & & & &
\end{tabular}




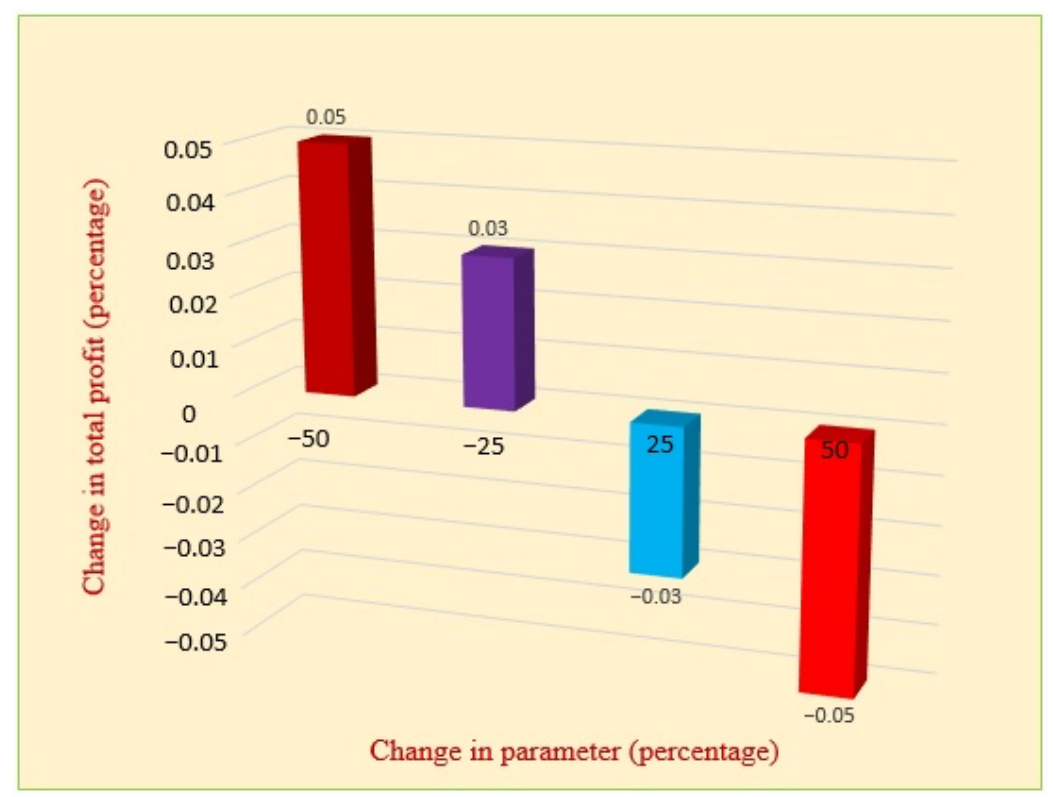

Figure 7. Effects of changes in parametric values versus total expected profit for the most sensitive parameter $R_{0}$.

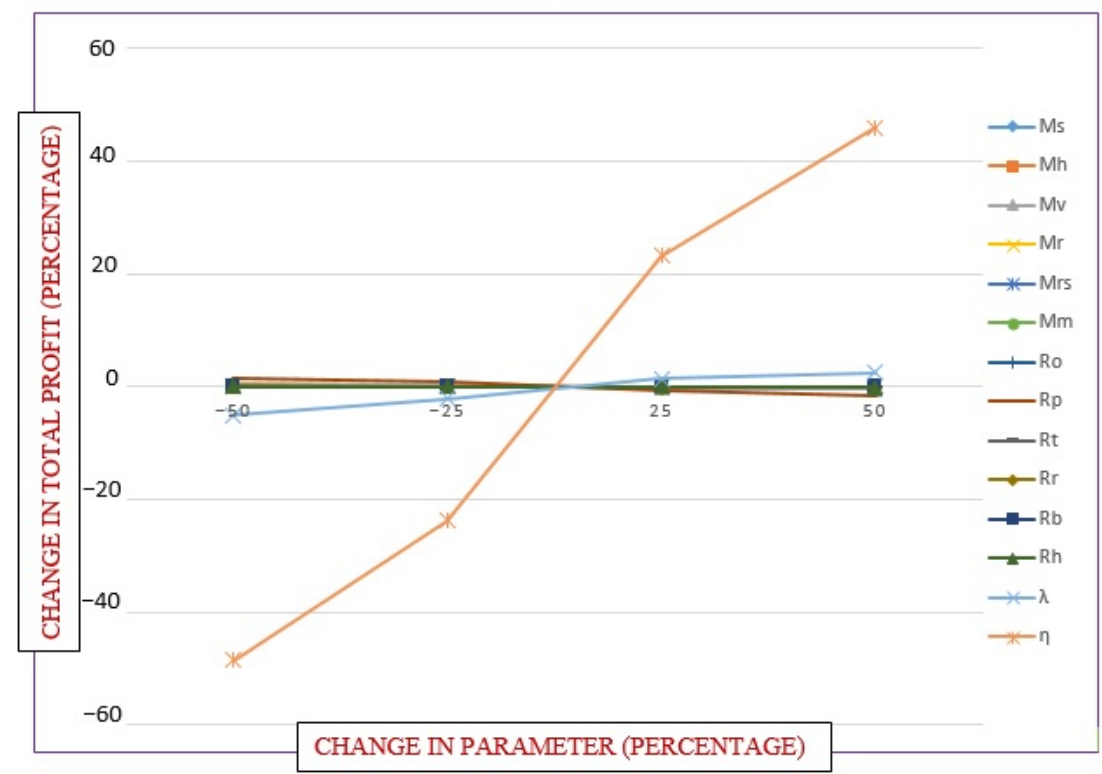

Figure 8. Effects of changes in parametric values versus total expected profit.

1. The sensitivity table clearly shows that the retailer's purchasing cost per unit has more impact than the other costs. Due to its decreasing nature, automatically retailers' total cost decreases, and profit increases and vise versa. Whenever the retailer pays more purchasing costs for a sing product, the profit margin decreases, it is because all the other costs and selling price of the retailer remain the same. Hence the profit goes down.

2. The restoration cost has an impact on the total expected profit of the system. Its increasing value decreases the production rate, and naturally, the total expected profit gradually reduces. Meanwhile, the machines' cost for smart production and its maintenance is generally higher than the traditional one. Nevertheless, in general, the rate of failure of smart machines is less than traditional machines.

3 . The other cost parameters have an equivalent impact on the total expected profit. The increasing value of the parameters increases the joint total cost and vice versa. Hence, automatically the total expected profit decreases and vise versa. 


\section{Managerial Insights}

The followings are the recommendations for improving the managerial decision of the industry.

1. An essential matter is the preventive maintenance policy. The manager should maintain the investment for such a case to reduce defective production. Besides, a small amount of investment for the instrumental inspection's regular check-up can control a big problem. Even if any recovery is needed immediately during the non-production time, that can be controlled. Thus, machinery safety should be the focus of any production authority.

2. Restoration investment is another vital matter of any production system. The outof-control situation can hamper the production process in both directions, by time and cost. It reduces the production rate as well decreases the total expected profit. The defective product can dismiss the excellent reputation of the brand. Thus, the industry manager should focus on the restoration of the machinery system to hold its reputation.

3. Another essential matter is the rework cost. This cost involves remaking the non-conforming products and delivers to the market with a warranty period. Besides, reworked products increase the total expected profit. Therefore industrial section should give importance to this matter.

4. For the smart production system, smart products' warranty plays an essential role in this competitive market. Warranty policy increases customer satisfaction and the excellent reputation of the company. Even the product is reworked rather than a wasted product. The warranty policy makes the products reliable on the market. Thus, every smart product industry should improve its warranty policy.

5. Here, another important direction is the freight cost per consignment. It is increasing value decreases the shipment number and increases the shifted quantity and backorder quantity also. Thus, the industry should reduce the number of shipments because it increases transportation cost. However, they should increase the lot size in each shipment. Hence, the industry manager can increase the expected total profit if the industry can maintain the above-specified instructions.

\section{Conclusions}

This model proved the best way of maintenance policy under the optimum energy consumption. Here, the model highlighted the demand pattern, dependent on the selling price and energy consumption, and variable production rate. The study focused on restoration costs and preventive maintenance costs to reduce the out-of-control situation. This model's main goal was to obtain the maximum joint profit by simultaneously optimizing decision variables: the number of consignments, size of shipment, backordering products, selling price, and production rate. Two propositions were established for the global optimal solution of the model. Mathematica 9.0 was used as a numerical tool to find the numerical results, total expected profit, and to prove the global optimal solution of the decision variables. It was found that smart products could quickly provide a significant profit. This study can be applied to any smart product company. It was proved that as the discard of the defective product can create a loss, the rework played an essential role for the joint profit. Thus, after reworking, that product can be sold again with the warranty policy.

Finally, this study has highlighted the significance of selling price and energy consumption based on customer demand pattern, preventive maintenance policy, restoration actions, warranty, and imperfect manufacturing system with variable production rate. Since the variable production was being controlled through the smart production process and in the case of machine-driven production, large amounts of carbon emissions were emitted and destroyed the environment by huge carbon emission. This study reduced the amount of carbon emission by the recommended strategy (Sarkar et al. [31]). Besides, in smart products, the investment for service is a particular aspect through which customers will be attracted. This can be a possible extension of this model. It can further be extended by stock- or advertisement-dependent demand (Noh et al. [37]). This model may be expanded by considering the green quality of products (Tiwari et al. [23]), lead time, 
and transportation discount (Shin et al. [22]). The combination of inspection policy and inspection errors will further increase the robustness of this model. Above all, an advanced sustainable model can be made as an extension of this model.

Author Contributions: Data curation, B.S., S.B., S.P. and B.K.S.; software, B.S. and S.B.; formal analysis, B.S., S.B. and B.K.S.; investigation, S.B., B.K.S. and S.P.; writing-original draft preparation, B.S., S.B. and S.P.; conceptualization, B.S. and S.B. methodology, B.S., S.B. and S.P.; validation, B.S., S.B. and B.K.S.; visualization B.S., S.B. and S.P.; supervision, B.S., S.B. and S.P.; writing-review and editing, B.S., S.B. and S.P. All authors have read and agreed to the published version of the manuscript.

Funding: This research received no external funding.

Conflicts of Interest: The authors declare no conflict of interest.

\section{Abbreviations}

The following abbreviations are used in this manuscript:

$\begin{array}{ll}\text { SCM } & \text { Supply chain management } \\ \text { OC } & \text { Out-of-control } \\ \text { IC } & \text { In-control } \\ \text { QI } & \text { Quality improvement } \\ \text { SCR } & \text { Setup cost reduction } \\ \text { NCI } & \text { non-conforming products } \\ \text { TEP } & \text { Total expected profit } \\ \text { JTC } & \text { Joint total cost } \\ \text { EMQ } & \text { Economic manufacturing quantity } \\ \text { EPQ } & \text { Economic production quantity } \\ \text { EOQ } & \text { Economic order quantity } \\ \text { SSMD } & \text { single-setup multiple-delivery } \\ \text { SPECD } & \text { Selling price and energy consumption dependent demand } \\ \text { SPADD } & \text { Selling price and advertisement dependent demand } \\ \text { SPQDD } & \text { Selling price and quality dependent demand } \\ \text { SPD } & \text { Selling price dependent } \\ \text { SPWGDD } & \text { Selling price, warranty dependent demand }\end{array}$

\section{Appendix A}

$\operatorname{TEP}()=.\operatorname{TEP}(P, p, \zeta, \xi)$

"The first order partial derivatives with respect to the decision variables" are

$$
\begin{aligned}
\frac{\partial T E P(.)}{\partial P} & =-\frac{D}{m \zeta}\left[M_{h}\left(\frac{m^{2} \zeta^{2}}{2 P^{2}}-\frac{m \zeta^{2}}{P^{2}}\right)+(\theta+\phi)\left\{\frac{2}{m \zeta}\left(e^{-\frac{m \zeta}{2 P}}-1\right)+\frac{1}{P} e^{-\frac{m \zeta}{2 P}}\right\}-M_{r s} \frac{\zeta m \zeta}{P^{2}} e^{-\frac{\zeta m \zeta}{P}}\right] \\
\frac{\partial T E P(.)}{\partial p} & =\lambda \frac{\left(p_{\min }-p_{\text {max }}\right)}{\left(p-p_{\text {min }}\right)^{2}}(p-J T C)+D\left[1+\lambda \frac{\left(p_{\min }-p_{\max }\right)}{D^{2}\left(p-p_{\min }\right)^{2}}\left\{M_{h}(m-1) \zeta\right.\right. \\
& \left.\left.-\left(\frac{R_{b} m \xi^{2}}{2}+\frac{R_{h} m(\zeta-\xi)^{2}}{2}\right)\right\}\right] \\
\frac{\partial T E P(.)}{\partial \zeta}= & \frac{D}{m \zeta^{2}}(J T C)-\frac{D}{m \zeta}\left[\omega+2 M_{h} \zeta\left(\frac{m}{P}-\frac{m^{2}}{2 P}+\frac{m(m-1)}{2 D}\right)+\frac{R_{h} m \zeta}{D}\right] \\
\frac{\partial T E P(.)}{\partial \xi} & =\frac{1}{\zeta}\left[R_{h}(\zeta-\xi)-R_{b} \xi\right]
\end{aligned}
$$

\section{Appendix B}

$$
\begin{gathered}
\operatorname{TEP}(.)=\operatorname{TEP}(P, p, \zeta, \xi) \\
\text { “The second order partial derivatives with respect to the decision variables" are } \\
\frac{\partial^{2} T E P(.)}{\partial P^{2}}=-\frac{D}{m \zeta}\left[\frac{M_{h} m \zeta^{2}}{P^{3}}(2-m)+(\theta+\phi) \frac{e^{-\frac{m \zeta}{2 P}}}{p^{2}}\left(2+\frac{m \zeta}{2 P}\right)+\frac{M_{r s} \zeta \zeta}{P^{3}} e^{-\frac{\varsigma m \zeta}{P}}\left(2+\frac{\varsigma m \zeta}{P}\right)\right]=\Phi_{1}(\text { say })
\end{gathered}
$$




$$
\begin{aligned}
& \frac{\partial^{2} \operatorname{TEP}(.)}{\partial p^{2}}=\frac{2 \lambda\left(p_{\max }-p_{\min }\right)}{\left(p-p_{\min }\right)^{2}}\left[\frac{(p-J T C)}{\left(p-p_{\min }\right)}-\left\{1+\lambda \frac{\left(p_{\min }-p_{\max }\right)}{D^{2}\left(p-p_{\min }\right)^{2}}\left\{M_{h}(m-1)\right\}\right.\right. \\
& \left.\left.\left.-\left(\frac{R_{b} m \xi^{2}}{2}+\frac{R_{h} m(\zeta-\xi)^{2}}{2}\right)\right\}\right\}\right]+\frac{2 \lambda}{D} \frac{\left(p_{\max }-p_{\min }\right)}{\left(p-p_{\min }\right)^{2}}\left\{\frac{1}{\left(p-p_{\min }\right)}-\frac{\lambda}{D}\left(P_{\max }-P_{\min }\right)\right\} \\
& \times\left\{1+\lambda \frac{\left(p_{\min }-p_{\max }\right)}{D^{2}\left(p-p_{\min }\right)^{2}}\left\{M_{h}(m-1) \zeta-\left(\frac{R_{b} m \xi^{2}}{2}+\frac{R_{h} m(\zeta-\xi)^{2}}{2}\right)\right\}\right\}=\Phi_{2}(\text { say }) \\
& \frac{\partial^{2} \operatorname{TEP}(.)}{\partial \zeta^{2}}=\frac{2 D}{m \zeta^{2}}\left[\omega+2 M_{h} \zeta\left(\frac{m}{P}-\frac{m^{2}}{2 P}+\frac{m(m-1)}{2 D}\right)+\frac{R_{h} m \zeta}{D}-(J T C)\right] \\
& -\frac{D}{m \zeta}\left[2 m M_{h}\left(\frac{m}{P}-\frac{m^{2}}{2 P}+\frac{m(m-1)}{2 D}\right)-2 m M_{r}\left(\psi_{2}-\psi_{1}\right)\left\{\frac{2 P}{m \zeta^{2}}\left(e^{-\frac{m \zeta}{2 P}}-1\right)-\frac{1}{\zeta} e^{-\frac{m \zeta}{2 P}}\right\}\right. \\
& +(\theta+\phi) m \zeta\left(M_{r}+M_{w}\right)\left\{\frac{4 P}{m \zeta^{3}}\left(e^{-\frac{m \zeta}{2 P}}-1\right)+\frac{1}{\zeta} e^{-\frac{m \zeta}{2 P}}\left(\frac{1}{\zeta}+\frac{m}{2 P}\right)\right\}-M_{r s} \frac{m^{2} \zeta^{2}}{P^{2}} e^{-\frac{m \zeta \zeta}{2 P}} \\
& \left.-\frac{2}{\zeta}(\theta+\phi)\left\{\frac{2 P}{m \zeta^{2}}\left(e^{-\frac{m \zeta}{2 P}}-1\right)+e^{-\frac{m \zeta}{2 P}}\right\}+\frac{R_{h} m}{D}\right]=\Phi_{3}(\text { say }) \\
& \frac{\partial^{2} \operatorname{TEP}(.)}{\partial \xi^{2}}=-\frac{\left(R_{h}+R_{b}\right)}{\zeta}=\Phi_{4}(\text { say }) \\
& \frac{\partial^{2} \operatorname{TEP}(.)}{\partial P \partial p}=\frac{\partial^{2} \operatorname{TEP}(.)}{\partial p \partial P}=-\frac{\lambda\left(p_{\min }-p_{\max }\right)}{m \zeta\left(p-p_{\min }\right)^{2}}\left[\frac{M_{h} m \zeta^{2}}{P^{2}}\left(\frac{m}{2}-1\right)\right. \\
& \left.+(\theta+\phi)\left\{\frac{2}{m \zeta}\left(e^{-\frac{m \zeta}{2 P}}-1\right)-\frac{1}{P} e^{-\frac{m \zeta}{2 P}}\right\}-M_{r s} \frac{m \zeta \zeta}{P^{2}} e^{-\frac{m \zeta \zeta}{P}}\right]=\Phi_{5}(\text { say }) \\
& \frac{\partial^{2} T E P(.)}{\partial P \partial \zeta}=\frac{\partial^{2} T E P(.)}{\partial \zeta \partial P}=\frac{D}{m \zeta^{2}}\left[M_{h}\left(\frac{m^{2} \zeta^{2}}{2 P^{2}}-\frac{m \zeta^{2}}{P^{2}}\right)+(\theta+\phi)\left\{\frac{2}{m \zeta}\left(e^{-\frac{m \zeta}{2 P}}-1\right)+\frac{1}{P} e^{-\frac{m \zeta}{2 P}}\right\}\right. \\
& -M_{r s} \frac{\varsigma m \zeta}{P^{2}} e^{-\frac{c m \zeta}{P}}-\left\{\frac{M_{h} m \zeta^{2}}{P^{2}}(m-2)-(\theta+\phi)\left\{\frac{2}{m \zeta^{2}}\left(e^{-\frac{m \zeta}{2 P}}-1\right)\right.\right. \\
& \left.+\frac{1}{P \zeta} e^{-\frac{m \zeta}{2 P}}+\frac{m}{2 P^{2}} e^{-\frac{m \zeta}{2 P}}\right\}+\frac{1}{\zeta}(\theta+\phi)\left\{\frac{2}{m \zeta}\left(e^{-\frac{m \zeta}{2 P}}-1\right)+\frac{1}{P} e^{-\frac{m \zeta}{2 P}}\right\} \\
& \left.\left.-\quad M_{r s} \frac{m \zeta}{P^{2}} e^{-\frac{m \zeta}{2 P}}\left(1-\frac{m \zeta \zeta}{P}\right)\right\}\right]=\Phi_{6}(\text { say }) \\
& \frac{\partial^{2} T E P(.)}{\partial P \partial \xi}=\frac{\partial^{2} T E P(.)}{\partial \xi \partial P}=0 \\
& \frac{\partial^{2} T E P(.)}{\partial p \partial \zeta}=\frac{\partial^{2} T E P(.)}{\partial \zeta \partial p}=\frac{\lambda}{m \zeta^{2}} \frac{\left(p_{\min }-p_{\max }\right)}{\left(p-p_{\min }\right)^{2}}\left[(J T C)-\zeta\left\{\omega+2 M_{h} \zeta\left(\frac{m}{P}-\frac{m^{2}}{2 P}+\frac{m(m-1)}{2 D}\right)\right.\right. \\
& \left.\left.+\frac{R_{h} m \zeta}{D}\right\}+\zeta\left(\frac{m(m-1)}{2 D}+\frac{R_{h} m(\zeta-\xi)}{D}\right)\right]=\Phi_{7}(\text { say }) \\
& \begin{array}{l}
\frac{\partial^{2} \operatorname{TEP}(.)}{\partial p \partial \xi}=\frac{\partial^{2} \operatorname{TEP}(.)}{\partial \xi \partial p}=0 \\
\frac{\partial^{2} \operatorname{TEP}(.)}{\partial \zeta \partial \xi}=\frac{\partial^{2} \operatorname{TEP}(.)}{\partial \xi \partial \zeta}=\frac{1}{\zeta^{2}}\left[R_{b} \xi-R_{h}(\zeta-\xi)\right]+\frac{R_{h}}{\zeta}=\Phi_{8}(\text { say })
\end{array} \\
& \left|H_{11}\right|=\left|\frac{\partial^{2} T E P(.)}{\partial P^{2}}\right| \\
& =-\frac{D}{m \zeta}\left[\frac{M_{h} m \zeta^{2}}{P^{3}}(2-m)+(\theta+\phi) \frac{e^{-\frac{m \zeta}{2 P}}}{p^{2}}\left(2+\frac{m \zeta}{2 P}\right)+\frac{M_{r s} \zeta m \zeta}{P^{3}} e^{-\frac{\varsigma m \zeta}{P}}\left(2+\frac{\varsigma m \zeta}{P}\right)\right] \\
& =\Phi_{1}
\end{aligned}
$$




$$
\begin{aligned}
& \left|H_{22}\right|=\left|\begin{array}{ll}
\frac{\partial^{2} T E P(.)}{\partial P^{2}} & \frac{\partial^{2} T E P(.)}{\partial P \partial p} \\
\frac{\partial^{2} T E P(.)}{\partial p \partial P} & \frac{\partial^{2} T E P(.)}{\partial p^{2}}
\end{array}\right|=\frac{\partial^{2} T E P(.)}{\partial P^{2}} \frac{\partial^{2} T E P(.)}{\partial p^{2}}-\left(\frac{\partial^{2} T E P(.)}{\partial P \partial p}\right)^{2} \\
& =\Phi_{1} \Phi_{2}-\Phi_{5}^{2} \\
& \left|H_{33}\right|=\mid \begin{array}{lll}
\frac{\partial^{2} T E P(.)}{\partial P^{2}} & \frac{\partial^{2} T E P(.)}{\partial P \partial p} & \frac{\partial^{2} T E P(.)}{\partial P \partial \zeta} \\
\frac{\partial^{2} T E P(.)}{\partial p \partial P} & \frac{\partial^{2} T E P(.)}{\partial p^{2}} & \frac{\partial^{2} T E P(.)}{\partial p \partial \zeta} \\
\frac{\partial^{2} T E P(.)}{\partial \zeta \partial P} & \frac{\partial^{2} T E P(.)}{\partial \zeta \partial p} & \frac{\partial^{2} T E P(.)}{\partial \zeta^{2}}
\end{array} \\
& =\Phi_{1}\left(\Phi_{2} \Phi_{3}-\Phi_{7}^{2}\right)-\Phi_{5}\left(\Phi_{5} \Phi_{3}-\Phi_{6} \Phi_{7}\right)+\Phi_{6}\left(\Phi_{5} \Phi_{7}-\Phi_{6} \Phi_{2}\right) \\
& \left|H_{44}\right|=\left|\begin{array}{llll}
\frac{\partial^{2} T E P(.)}{\partial P^{2}} & \frac{\partial^{2} T E P(.)}{\partial P \partial p} & \frac{\partial^{2} T E P(.)}{\partial P \partial \zeta} & \frac{\partial^{2} T E P(.)}{\partial P \partial \xi} \\
\frac{\partial^{2} T E P(.)}{\partial p \partial P} & \frac{\partial^{2} T E P(.)}{\partial p^{2}} & \frac{\partial^{2} T E P(.)}{\partial p \partial \zeta} & \frac{\partial^{2} T E P(.)}{\partial p \partial \xi} \\
\frac{\partial^{2} T E P(.)}{\partial \zeta \partial P} & \frac{\partial^{2} T E P(.)}{\partial \zeta \partial p} & \frac{\partial^{2} T E P(.)}{\partial \zeta^{2}} & \frac{\partial^{2} T E P(.)}{\partial \zeta \partial \xi} \\
\frac{\partial^{2} T E P(.)}{\partial \xi^{2}(.)} & \frac{\partial^{2} T E P(.)}{\partial \xi \partial p} & \frac{\partial^{2} T E P(.)}{\partial \xi \partial \zeta} & \frac{\partial^{2} T E P(.)}{\partial \xi^{2}}
\end{array}\right| \\
& =\Phi_{8}^{2}\left(\Phi_{5}^{2}-\Phi_{1} \Phi_{2}\right)+\Phi_{4} \Phi_{1}\left(\Phi_{2} \Phi_{3}-\Phi_{7}^{2}\right) \\
& -\Phi_{5} \Phi_{4}\left(\Phi_{5} \Phi_{3}-\Phi_{6} \Phi_{7}\right)+\Phi_{6} \Phi_{4}\left(\Phi_{5} \Phi_{7}-\Phi_{6} \Phi_{2}\right)
\end{aligned}
$$

\section{References}

1. Sarkar, B. Mathematical and analytical approach for the management of defective items in a multi-stage production system. J. Clean. Prod. 2019, 218, 896-919. [CrossRef]

2. Dey, B.K.; Sarkar, B.; Sarkar, M.; Pareek, S. An integrated inventory model involving discrete setup cost reduction, variable safety factor, selling-price dependent demand, and investment. RAIRO Oper. Res. 2019, 53, 39-57. [CrossRef]

3. Cárdenas-Barrón, L.E.; Sarkar, B.; Treviño-Garza, G. Easy and improved algorithms to joint determination of the replenishment lot size and number of shipments for an EPQ model with rework. Math. Comput. Appl. 2013, 18, 132-138. [CrossRef]

4. Cárdenas-Barrón, L.E.; Sarkar, B.; Treviño-Garza, G. An improved solution to the replenishment policy for the EMQ model with rework and multiple shipments. Appl. Math. Model. 2013, 37, 5549-5554. [CrossRef]

5. Sarkar, B.; Guchhait, R.; Sarkar, M.; Cárdenas-Barrón, L.E. How does an industry manage the optimum cash flow within a smart production system with the carbon footprint and carbon emission under logistics framework? Int. J. Prod. Econ. 2019, 213, 243-257. [CrossRef]

6. Nakagawa, T. A summary of imperfect preventive maintenance policies with minimal repair. RAIRO Oper. Res. 1980, 14, 249-255 [CrossRef]

7. Sana, S.S. Preventive maintenance and optimal buffer inventory for products sold with warranty in an imperfect production system. Int. J. Prod. Res. 2012, 50, 6763-6774. [CrossRef]

8. Khanna, A.; Gautam, P.; Sarkar, B.; Jaggi, C.K. Integrated vendor-buyer strategies for imperfect production systems with maintenance and warranty policy. RAIRO Oper. Res. 2020, 54, 435-450. [CrossRef]

9. Sana, S.S. An economic production lot size model in an imperfect production system. Eur. J. Oper. Res. 2010, 201, 158-170. [CrossRef]

10. Khan, I.; Jemai, J.; Lim, H.; Sarkar, B. Effect of electrical energy on the manufacturing setup cost reduction, transportation discounts, and process quality improvement in a two-echelon supply chain management under a service-level constraint. Energies 2019, 12, 3733. [CrossRef]

11. Bhuniya, S.; Sarkar, B.; Pareek, S. Multi-product production system with the reduced failure rate and the optimum energy consumption under variable demand. Mathematics 2019, 7, 465. [CrossRef]

12. Dey, B.K.; Pareek, S.; Tayyab, M.; Sarkar, B. Autonomation policy to control work-in-process inventory in a smart production system. Int. J. Prod. Res. 2020. [CrossRef]

13. Sarkar, M.; Sarkar, B. How does an industry reduce waste and consumed energy within a multi-stage smart sustainable biofuel production system? J. Clean. Prod. 2020, 262, 121200. [CrossRef]

14. Saxena, N.; Sarkar, B.; Singh, S.R. Selection of remanufacturing/production cycles with an alternative market: A perspective onwaste management. J. Clean. Prod. 2020, 245, 118935. [CrossRef]

15. Sarkar, M.; Pan, L.; Dey, B.K.; Sarkar, B. Does the autonomation policy really help in a smart production system for controlling defective production? Mathematics 2020, 8, 1142. [CrossRef]

16. Hsu, J.T.; Hsu, L.F. An integrated vendor-buyer cooperative inventory model in an imperfect production process with shortage backordering. Int. J. Adv. Manuf. Technol. 2013, 65, 493-505. [CrossRef]

17. Jiao, C.; Zhu, X. Optimal design of sales and maintenance under the renewable warranty. RAIRO Oper. Res. 2018, 52, 529-542. [CrossRef] 
18. Wee, H.M.; Wang, W.T.; Cárdenas-Barrón, L.E. An alternative analysis and solution procedure for the EPQ model with rework process at a single-stage manufacturing system with planned backorders. Comput. Ind. Eng. 2013, 64, 748-755. [CrossRef]

19. Sarkar, B.; Cárdenas-Barrón, L.E.; Sarkar, M.; Singgih, M.L. An economic production quantity model with random defective rate,rework process and backorders for a single stage production system. J. Manuf. Syst. 2014, 33, 423-435. [CrossRef]

20. Sarkar, B.; Moon, I. Improved quality, setup cost reduction, and variable backorder costs in an imperfect production process. Int. J. Prod. Econ. 2014, 155, 204-213. [CrossRef]

21. Liu, X.; Wang, W.; Peng, R. An integrated production, inventory and preventive maintenance model for a multi-product production system. Reliab. Eng. Syst. Saf. 2015, 137, 76-86. [CrossRef]

22. Shin, D.; Guchhait, R.; Sarkar, B.; Mittal, M. Controllable lead time, service level constraint, and transportation discounts in a continuous review inventory model. RAIRO Oper. Res. 2016, 50, 921-934. [CrossRef]

23. Tiwari, S.; Ahmed, W.; Sarkar, B. Multi-item sustainable green production system under trade-credit and partial backordering. J. Clean. Prod. 2018, 204, 82-95. [CrossRef]

24. Kim, M.S.; Kim, J.S.; Sarkar, B.; Sarkar, M.; Iqbal, M.W. An improved way to calculate imperfect items during long-run production in an integrated inventory model with backorders. J. Manuf. Syst. 2018, 47, 153-167. [CrossRef]

25. Sarkar, B.; Dey, B.K.; Pareek, S.; Sarkar, M. A single-stage cleaner production system with random defective rate and remanufacturing. Comput. Ind. Eng. 2020, 106861. [CrossRef]

26. Taleizadeh, A.A.; Sarkar, B.; Hasani, M. Delayed payment policy in multi-product single-machine economic production quality model with repair failure and partial backordering. J. Ind. Manag. Optim. 2020, 16, 1273-1296. [CrossRef]

27. Guchhait, R.; Dey, B.K.; Bhuniya, S.; Ganguly, B.; Mandal, B.; Bachar, R.; Sarkar, B.; Wee, H.; Chaudhuri, K. Investment for process quality improvement and setup cost reduction in an imperfect production process with warranty policy and shortages. RAIRO Oper. Res. 2020, 54, 251-266. [CrossRef]

28. Mishra, U.; Sarkar, B.; Wu, J.Z. Optimum sustainable inventory management with backorder and deterioration under controllable carbon emissions. J. Clean. Prod. 2021, 279, 123699. [CrossRef]

29. Giri, B.C.; Dohi, T. Computational aspects of an extended EMQ model with variable production rate. Comput. Oper. Res. 2005, 32, 3143-3161. [CrossRef]

30. Chang, H.J.; Su, R.H.; Yang, C.T.; Weng, M.W. An economic manufacturing quantity model for a two-stage assembly system with imperfect processes and variable production rate. Comput. Ind. Eng. 2012, 63, 285-293. [CrossRef]

31. Sarkar, B.; Saren, S.; Sarkar, M.; Seo, Y.W. A Stackelberg game approach in an integrated inventory model with carbon-emission and setup cost reduction. Sustainability 2016, 8, 1244. [CrossRef]

32. Alduragam, M.; Adegbola, K.; Glock, C.H. A single-vendor single-manufacturer integrated inventory model with stochastic demand and variable production rate. Int. J. Prod. Econ. 2017, 191, 335-350. [CrossRef]

33. Majumder, A.; Jaggi, C.K.; Sarkar, B. A multi-retailer supply chain model with backorder and variable production cost. RAIRO Oper. Res. 2018, 52, 943-954. [CrossRef]

34. Dey, B.K.; Sarkar, B.; Pareek, S. A two-echelon supply chain managementWith setup time and cost reduction, quality improvement and variable production rate. Mathematics 2019, 7, 328. [CrossRef]

35. Wu, K.S.; Ouyang, L.Y.; Yang, C.T. An optimal replenishment policy for non-instantaneous deteriorating items with stockdependent demand and partial backlogging. Int. J. Prod. Econ. 2006, 101, 369-384. [CrossRef]

36. Feng, L.; Chan, Y.L.; Cárdenas-Barrón, L.E. Pricing and lot-sizing polices for perishable goods when the demand depends on selling price, displayed stocks, and expiration date. Int. J. Prod. Econ. 2016, 185, 11-20. [CrossRef]

37. Noh, J.S.; Kim, J.S.; Sarkar, B. Two-echelon supply chain coordination with advertising demand under Stackelberg game policy. Eur. J. Ind. Eng. 2019, 13, 213-244. [CrossRef]

38. Meng, J.; Hu, X.; Chen, P.; Coffman, D.M.; Han, M. The unequal contribution to global energy consumption along the supply chain. J. Environ. Manag. 2020, 268, 110701. [CrossRef]

39. Sarkar, B.; Dey, B.K.; Sarkar, M.; Hur, S.; Mandal, B.; Dhaka, V. Optimal repleshment decision for retailers with variable demand for deteriorating products under a trade-credit policy. RAIRO Oper. Res. 2020, 54, 1685-1701. [CrossRef]

40. Malik, A.I.; Sarkar, B. Coordination supply chain management under flexible manufacturing, stochastic leadtime demand, and mixture of inventory. Mathematics 2020, 8, 911. [CrossRef]

41. Pal, B.; Sana, S.S.; Chaudhuri, K. A multi-echelon supply chain model for reworkable items in multiple-markets with supply disruption. Econ. Model. 2012, 29, 1891-1898. [CrossRef]

42. Rad, A.R.; Khoshalhan, F.; Glock, C.H. Optimizing inventory and sales decisions in a two-stage supply chain with imperfect production and backorders. Comput. Ind. Eng. 2014, 74, 219-227. [CrossRef]

43. Habib, M.S.; Sarkar, B. An integrated location-allocation model for temporary disaster debris management under an uncertain environment. Sustainability 2017, 9, 716. [CrossRef]

44. Giri, B.C.; Mondal, C.; Maity, T. Analysing a closed-loop supply chain with selling price, warranty period and green sensitive consumer demand under revenue sharing contract. J. Clean. Prod. 2018, 190, 822-837. [CrossRef] 